\title{
Influence of Ultrasonication of Functionalized Carbon Nanotubes on the Rheology, Hydration, and Compressive Strength of Portland Cement Pastes
}

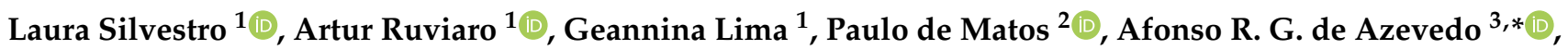 \\ Sérgio Neves Monteiro ${ }^{4}$ and Philippe Gleize ${ }^{1}$ \\ 1 Department of Civil Engineering, Federal University of Santa Catarina (UFSC), \\ Florianópolis 88040-900, Brazil; laura.silvestro@posgrad.ufsc.br (L.S.); artur.spat@posgrad.ufsc.br (A.R.); \\ geannina.lima@posgrad.ufsc.br (G.L.); p.gleize@ufsc.br (P.G.) \\ 2 Coordenadoria Acadêmica, Federal University of Santa Maria (UFSM), Cachoeira do Sul 96503-205, Brazil; \\ paulorm.matos@gmail.com \\ 3 LECIV-Civil Engineering Laboratory, UENF—State University of the Northern Rio de Janeiro, Av. Alberto \\ Lamego, 2000, Campos dos Goytacazes 28013-602, Brazil \\ 4 Military Engineering Institute, IME-Materials Science Program, Praça Gen. Tibúrcio, 80, Urca, \\ Rio de Janeiro 22290-270, Brazil; snevesmonteiro@gmail.com \\ check for \\ * Correspondence: afonso@uenf.br
} updates

Citation: Silvestro, L.; Ruviaro, A.; Lima, G.; de Matos, P.; de Azevedo, A.R.G.; Monteiro, S.N.; Gleize, P. Influence of Ultrasonication of Functionalized Carbon Nanotubes on the Rheology, Hydration, and Compressive Strength of Portland Cement Pastes. Materials 2021, 14 , 5248. https://doi.org/10.3390/ma 14185248

Academic Editors: Qiang Zeng, Chunsheng Zhou, Zhendi Wang, Jiyang Wang, Dongming Yan and Shaoqin Ruan

Received: 9 August 2021

Accepted: 2 September 2021

Published: 13 September 2021

Publisher's Note: MDPI stays neutral with regard to jurisdictional claims in published maps and institutional affiliations.

Copyright: (c) 2021 by the authors. Licensee MDPI, Basel, Switzerland. This article is an open access article distributed under the terms and conditions of the Creative Commons Attribution (CC BY) license (https:// creativecommons.org/licenses/by/ $4.0 /)$.
Abstract: The functionalization process usually increases the localized defects of carbon nanotubes (CNT). Thus, the ultrasonication parameters used for dispersing non-functionalized CNT should be carefully evaluated to verify if they are adequate in dispersing functionalized CNT. Although ultrasonication is widely used for non-functionalized CNT, the effect of this dispersing process of functionalized CNT has not been thoroughly investigated. Thus, this work investigated the effect of ultrasonication on functionalized CNT + superplasticizer (SP) aqueous dispersions by ultraviolet-visible (UV-Vis) spectroscopy, dynamic light scattering (DLS), and Fourier transform infrared spectroscopy (FTIR). Furthermore, Portland cement pastes with additions of $0.05 \%$ and $0.1 \%$ CNT by cement weight and ultrasonication amplitudes of $0 \%, 50 \%$ and $80 \%$ were evaluated through rheometry, isothermal calorimetry, compressive strength at 1,7 and 28 days, $X$-ray diffraction (XRD), and thermogravimetric analysis (TGA). FTIR results from CNT + SP dispersions indicated that ultrasonication may negatively affect SP molecules and CNT graphene structure. The increase in CNT content and amplitude of ultrasonication gradually increased the static and dynamic yield stress of paste but did not significantly affect its hydration kinetics. Compressive strength results indicated that the optimum CNT content was $0.05 \%$ by cement weight, which increased the strength of composite by up to $15.8 \%$ compared with the plain paste. CNT ultrasonication neither increases the degree of hydration of cement nor the mechanical performance of composite when compared with mixes containing unsonicated CNT. Overall, ultrasonication of functionalized CNT is not efficient in improving the fresh and hardened performance of cementitious composites.

Keywords: carbon nanotube; ultrasonication; hydration; rheology; compressive strength

\section{Introduction}

The use of carbon nanotubes (CNT) is still limited due to difficulties associated with the dispersion of these nanomaterials and their weak interaction with cementitious matrix. This is because CNT, unlike other spherical particles and carbon fibers, are characterized by small nanometric diameters, high aspect ratio (>1000), and, therefore, a large surface area $[1,2]$. The effect of CNT on the mechanical performance of cement-based materials is not a consensus in the literature. $[3,4]$. Some authors have reported that CNT significantly increased the mechanical performance of cementitious composites. By contrast, other 
authors have observed decreases in these properties [4]. Mohsen et al. [3] attribute these divergences to inefficient CNT dispersion.

CNT dispersion can be carried out using physical and chemical methods. Ultrasonication, ball milling, magnetic stirring, among others can be classified as physical methods. Furthermore, according to the bond type that occurs on the CNT surface, the chemical methods can be subdivided into covalent and non-covalent functionalization [5]. According to Liew et al. [5], the most commonly used methods in experimental research to disperse CNT in water are ultrasonication and dispersant agents.

According to a survey carried out by Silvestro and Gleize [6] which evaluated 99 works related to use of CNT in cementitious matrix, most works used ultrasonication and dispersant agents to disperse the nanomaterial. Polycarboxylate-based admixtures are the most used type, identified in $40 \%$ of those works. Besides CNT dispersion, polycarboxylate-based admixtures are also used to ensure the workability of cement mixes.

The use of dispersant agents for CNT dispersion can be classified as a non-covalent functionalization process, with the main feature of not modifying the original structure of CNT. Banerjee et al. [7] reported that this type of functionalization avoid changes in the $\mathrm{sp}^{2}$ CNT structure.

The ultrasonication process aims to disperse nanomaterials through the application of ultrasound energy. The dispersion of CNT agglomerates occurs due to the implosion of microbubbles. There are two types of equipment used in ultrasonication, named ultrasound bath and ultrasound tip. In this context, the ultrasound tip promotes better dispersion of the CNT, as it provides a denser amount of energy [5].

The energy applied in the CNT dispersion process must be carefully evaluated, considering that if it is excessive it can cause the breakage of CNT and, thus, reduce the efficiency of incorporation of the nanomaterial on the mechanical performance of cement-based materials [8]. Jarolim et al. [8] found the value of $800 \mathrm{~J} / \mathrm{mL}$ to be the optimal amount of ultrasonic energy for CNT dispersion through UV-Vis spectroscopy. This energy resulted in a well-dispersed CNT dispersion, as observed by optical microscopy, and increased the compressive and flexural strengths at 7 and 28 days of curing mortars. However, it is worth noting that alkaline environments, such as cement pore solution, affect the stability of aqueous CNT dispersions [9]. Thus, the dispersion of CNT in aqueous solution can change when in contact with cement particles. Therefore, the behavior of CNT in aqueous solutions cannot be extrapolated for CNT dispersion in cementitious composites.

According to Zou et al. [10], the optimal ultrasonication energy balances the degree of dispersion and the shortening of CNT agglomerates to achieve superior mechanical properties. Regarding the dispersion in water assessed by UV-Vis spectroscopy, Zou et al. [10] observed that the absorbance, directly related to the degree of dispersion of the CNT aqueous solution, gradually increases with increasing ultrasonication energy until reaching a plateau between 150 and $250 \mathrm{~J} / \mathrm{mL}$. In turn, considering the modulus of elasticity and flexural strength of cement pastes, the authors obtained the best mechanical performance with the energy ultrasonication value of $20 \mathrm{~J} / \mathrm{mL}$. The results obtained by these authors indicated that the optimum energies for aqueous dispersions and for cementitious composites were not the same. This reinforces the fragility of the extrapolation of behaviors observed in CNT aqueous solution for CNT dispersion in cementitious matrix.

Regarding the influence of the ultrasonication time, Isfahani, et al. [11] characterized the aqueous dispersions of non-functionalized CNT and $\mathrm{COOH}-\mathrm{CNT}$ through UV-Vis spectroscopy. The CNT were dispersed by ultrasonication for 0, 30, 60 and $120 \mathrm{~min}$. According to their results of UV-Vis spectroscopy, the best dispersion in water was obtained after $120 \mathrm{~min}$ for functionalized CNT. For non-functionalized CNT, it was obtained after $60 \mathrm{~min}$. No significant increases in the compressive and flexural strengths of mortars containing the two types of CNT were observed with longer ultrasonication times. These authors also indicated that the high dispersion of CNT in cementitious matrix was not obtained by using a high CNT dispersion. 
Siqueira and Gleize [12] analyzed the influence of amplitude (20\%, 50\% and $80 \%)$ and ultrasonication time $(6,30$ and $60 \mathrm{~min})$ on the dispersion of aqueous non-functionalized CNT dispersions and on mechanical properties of cementitious composites. The authors observed that the use of high energy combined with the short ultrasonication time (amplitude of $80 \%$ and duration of $6 \mathrm{~min}$ ) generated the best mechanical performance when compared with the reference (i.e., plain cement paste). With the increase of ultrasonication time, there was a clear reduction in compressive and flexural strength for all amplitudes, which is probably a consequence of the CNT damage. In this context, Alrekabi et al. [13] also mentioned that ultrasonication with high intensity (i.e., amplitude) for short periods leads to a better CNT dispersion and, therefore, to a greater efficiency in the mechanical reinforcement of cementitious composites.

It is also worth mentioning the lack of information regarding the parameters used in the CNT dispersion process via ultrasonication. This makes direct comparison of results complex and limits the reproduction of previously published studies [6,12]. Additionally, with the exception of the work from Isfahani et al. [11], other previously mentioned works $[10,12,13]$ evaluating the influence of ultrasonication energy on the mechanical properties of cementitious composites did not compare the effect of different ultrasonication times and amplitudes with composites with CNT that were not dispersed by ultrasonication. Furthermore, although some works [10-13] have evaluated the influence of CNT ultrasonication energy on the mechanical properties of cementitious composites, the effect of this dispersion process on aqueous CNT + SP solutions has not been thoroughly investigated. In that context, Assi et al. [14] mentioned that the ultrasonication of water molecules produce hydrogen peroxide $\left(\mathrm{H}_{2} \mathrm{O}_{2}\right)$, which reacts with the calcium hydroxide $\left[\mathrm{Ca}(\mathrm{OH})_{2}\right]$. The product formed by this reaction is calcium peroxide $\left(\mathrm{CaO}_{2}\right)$, a salt that can improve the compressive strength gain at early ages [14]. However, the effect of ultrasonication of superplasticizer (SP) molecules has not yet been reported.

Considering this gap in knowledge, the aim of this work is to elucidate the influence of the ultrasonication process on rheology, hydration kinetics, compressive strength, and microstructure of cementitious composites with functionalized CNT without ultrasonication and pastes with CNT that were previously ultrasonicated with two amplitudes $(50 \%$ and $80 \%)$ [12]. For this purpose, CNT dispersions were characterized by UV-Vis spectroscopy, dynamic light scattering (DLS), and Fourier transform infrared spectroscopy (FTIR). Additionally, rheological tests were conducted though rotational rheometry and the hydration kinetics was evaluated by isothermal calorimetry. Compressive strength of composites was determined at 1, 7 and 28 curing days. The microstructure was evaluated through X-ray diffraction (XRD) and thermogravimetric analysis (TGA).

\section{Originality}

The type of CNT most used in cementitious matrix is non-functionalized, which is usually dispersed by ultrasonication $[6,15,16]$. In this context, although some works have evaluated the influence of CNT ultrasonication energy on the mechanical properties of cementitious composites, the lack of characterization of the effect of this dispersion process in aqueous CNT + SP solutions is highlighted.

Furthermore, since the use of functionalized CNT is less usual, the effectiveness of using ultrasonication to disperse functionalized CNT and improve the fresh and hardened performance of cementitious composites has not been fully investigated. Finally, rheological characterizations and hydration kinetics evaluations of CNT-reinforced cement pastes are still relatively scarce and can also be highlighted as a significant contribution from this work.

\section{Materials and Methods}

\subsection{Materials}

Carboxyl multi-walled carbon nanotubes (CNT) were used in this experiment. CNT was supplied by Nanostructured \& Amorphous Materials Inc., and its base properties are 
shown in Table 1. The transmission electron microscopy (TEM, JEM-1011, Joel, Akishima, Japan) image of CNT is show in Figure 1. CNT exhibited an average diameter about 20-30 nm, in agreement with the information provided by the manufacturer. Furthermore, TEM image (Figure 1a) shows an agglomeration trend of CNT. The Raman spectroscopy of CNT was conducted in a Renishaw 2000 spectrometer. The results indicated that CNT have an $\mathrm{I}_{\mathrm{D}} / \mathrm{I}_{\mathrm{G}}$ ratio of 0.98 . The disorder band $(\mathrm{D})$ is generated by disorder attributed to $\mathrm{sp}^{3}$ hybridized carbon systems, while the graphite $(\mathrm{G})$ band is attributed to $\mathrm{sp}^{2}$ bonds. Thus, the $I_{D} / I_{G}$ ratio can be used to evaluate the short-range order of the CNT structure [17]. The $\mathrm{I}_{\mathrm{D}} / \mathrm{I}_{\mathrm{G}}$ ratio of the carboxyl-functionalized CNT used in this study is higher than the $\mathrm{I}_{\mathrm{D}} / \mathrm{I}_{\mathrm{G}}$ ratio of the non-functionalized $\mathrm{CNT}$ reported in previous studies. Batiston et al. [18] used non-functionalized CNT with an $\mathrm{I}_{\mathrm{D}} / \mathrm{I}_{\mathrm{G}}$ ratio of 0.89 . The non-functionalized CNT evaluated by Bogas et al. [19] showed an $\mathrm{I}_{\mathrm{D}} / \mathrm{I}_{\mathrm{G}}$ ratio of 0.85 . These Raman results show that CNT functionalized with the carboxyl groups have a higher amount of localized defects in the $\mathrm{sp}^{2}$ network compared to non-functionalized CNT [20]. This suggests that the ultrasonication parameters used for dispersing non-functionalized CNT should be carefully evaluated to verify that they are adequate in dispersing functionalized CNT.

Table 1. CNT properties.

\begin{tabular}{cccccc}
\hline Inside Diameter $(\mathbf{n m})$ & Outside Diameter $(\mathbf{n m})$ & Length $(\boldsymbol{\mu m})$ & SSA $\left(\mathbf{m}^{2} / \mathbf{g}\right)$ & Purity & - COOH Content $(\%)$ \\
\hline $5-10$ & $20-30$ & $10-30$ & $>200$ & $95 \%$ & $1.9-2.1 \%$ \\
\hline
\end{tabular}
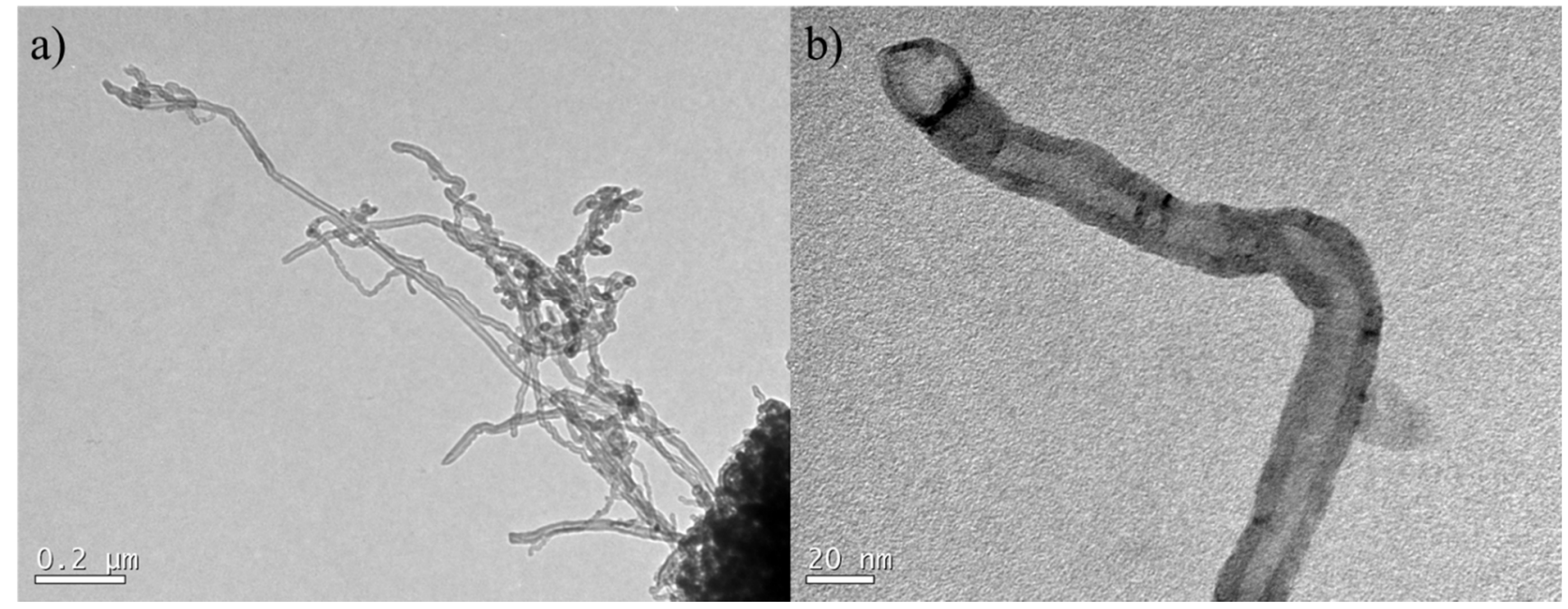

Figure 1. TEM images of the CNT used (a) $0.2 \mu \mathrm{m}$ range; (b) $20 \mathrm{~nm}$ range.

The admixture used for the dispersion of CNT was the polycarboxylate-based SP MC-PowerFlow 4000 supplied by Mc-Bauchemie. Figure 2 shows the FTIR characterization of the admixture. The test was performed on a liquid sample on a Cary 600 Series FTIR Spectrometer, with an analysis range of 500 to $4000 \mathrm{~cm}^{-1}$ and resolution of $2 \mathrm{~cm}^{-1}$. Characteristic functional groups of polycarboxylate-based SP were identified, such as spectrum ranges of $-\mathrm{OH}$ group, $\mathrm{C}-\mathrm{H}$ bond of aliphatic organic groups, carbonyl groups $(\mathrm{C}=\mathrm{O})$ and ether groups $(\mathrm{C}-\mathrm{O}-\mathrm{C})$ [21]. This SP admixture has a solid content of $42.1 \mathrm{wt} . \%$. 


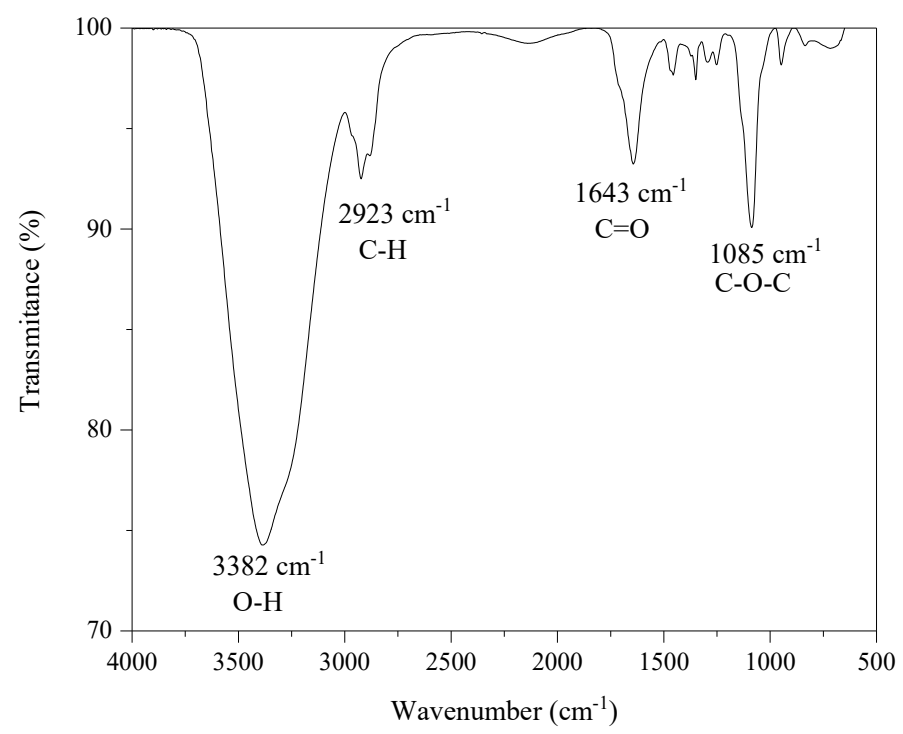

Figure 2. FTIR spectrum of the polycarboxylate-based superplasticizer used.

Ordinary Portland cement was used for paste production. The chemical composition of the cement presented in Table 2 was determined by X-ray fluorescence (XRF) in an EDX-7000 spectrometer (Shimadzu, Tokyo, Japan). The average diameter of Portland cement is $16.53 \mu \mathrm{m}$ and the density of $3.09 \mathrm{~g} / \mathrm{cm}^{3}$. The ordinary Portland Cement (OPC) was supplied by Itambé Cimentos (Balsa Nova-PR, Brazil).

Table 2. Chemical composition of Portland cement.

\begin{tabular}{|c|c|c|c|c|c|c|c|c|c|}
\hline Composition & $\mathrm{SiO}_{2}$ & $\mathrm{Al}_{2} \mathrm{O}_{3}$ & $\mathrm{Fe}_{2} \mathrm{O}_{3}$ & $\mathrm{CaO}$ & $\mathrm{K}_{2} \mathrm{O}^{\mathrm{a}}$ & $\mathrm{MgO}$ & $\mathrm{SO}_{3}$ & $\operatorname{LoI}^{b}$ & $\mathrm{IR}^{\mathrm{c}}$ \\
\hline wt.(\%) & 18.31 & 4.46 & 2.84 & 60.76 & 0.66 & 3.37 & 3.08 & 3.79 & 0.72 \\
\hline
\end{tabular}

\subsection{Mix Proportions}

Table 3 shows the compositions of the aqueous CNT dispersions evaluated. CNT contents of $0.05 \%$ and $0.1 \%$ by cement weight were evaluated [6]. The water/cement ratio $(\mathrm{w} / \mathrm{c}$ ) adopted was 0.4 since $\mathrm{CNT}$ incorporation is more effective in improving the mechanical strength of cementitious composites with low $\mathrm{w} / \mathrm{c}$ ratios [22]. The amount of $\mathrm{SP}$ was fixed at $0.2 \%$ by cement weight. This SP content was incorporated in all evaluated mixtures, including the control paste, i.e., without CNT addition (designated as REF). This value was defined based on the work from Cui et al. [23] since, as verified in UVVis spectroscopy, the content of polycarboxylate-based SP admixture that generated the best dispersions of CNT in aqueous solutions was found between 1:2 and 1:4 (NTC:SP, by weight). Furthermore, the SP content was fixed to evaluate the isolated effect of CNT incorporation in the cement pastes. This strategy has already been used by other researchers [24,25]. In addition, the effect of ultrasonication amplitude of CNT on the dispersion and mechanical properties of cementitious composites was studied. For this purpose, CNT solutions without ultrasonication (A0\%) and two ultrasonication amplitudes (A50\% and A $80 \%$ ) were evaluated. These parameters were defined based on previous works $[12,13]$. 
Table 3. Composition of CNT aqueous dispersions.

\begin{tabular}{ccccccc}
\hline CNT Dispersions & CNT (g) & Water (g) & SP (g) & Amplitude (\%) & Energy (J) & Energy (J/mL) \\
\hline $0.05 \%$ CNT-A0\% & 0.05 & 40.00 & 0.20 & - & - & - \\
$0.05 \%$ CNT-A50\% & 0.05 & 40.00 & 0.20 & 50 & 9356 & 234 \\
$0.05 \%$ CNT-A $80 \%$ & 0.05 & 40.00 & 0.20 & - & $-24,988$ & 628 \\
$0.1 \%$ CNT-A0\% & 0.10 & 40.00 & 0.20 & 50 & 9361 & 234 \\
$0.1 \%$ CNT-A50\% & 0.10 & 40.00 & 0.20 & 80 & 24,776 & 620 \\
$0.1 \%$ CNT-A80\% & 0.10 & 40.00 & 0.20 & & \\
\hline
\end{tabular}

\subsection{Aqueous CNT Dispersions Production and Characterization}

Initially, the appropriate amounts of CNT, deionized water, and SP were weighed, mixed, and ultrasonicated in a probe sonicator Vibra-Cell, VCX Serie, $750 \mathrm{~W}, 20 \mathrm{KHz}$, with diameter of $13 \mathrm{~mm}$ (Sonics \& Materials Inc., Newtown, CT, USA) with an amplitude of 50\% or $80 \%$ for $6 \mathrm{~min}$. The CNT dispersions were kept in an ice bath during ultrasonication to avoid increases in the temperature. CNT dispersions without ultrasonication were hand mixed for 2 min.

UV-Vis analyses were performed using a UV-5100S digital spectrophotometer. The CNT aqueous dispersions were diluted in deionized in the proportion of 1:100 [26] with magnetic stirring for $5 \mathrm{~min}$, to keep the absorbance values in the range of 0.1-2 in the entire wavelength range similar to the interval adopted by Attal et al. [27]. In aqueous solutions, the characteristic absorption of CNT occurs at $253 \mathrm{~nm}$ [28]. All spectra were obtained as a single scan in $10 \mathrm{~mm}$ quartz cuvettes, with a medium scan speed of $0.5 \mathrm{~nm}$ intervals, and analysis range from 200 to $600 \mathrm{~nm}$. Quartz cuvettes were used because they are more suitable for the CNT characteristic absorbance range, near to $253 \mathrm{~nm}$. Furthermore, deionized water was used as reference since tests were carried out with aqueous solutions with the same admixture concentration used to CNT dispersion, verifying that the admixture has no influence on the CNT characteristic wavelength $(253 \mathrm{~nm})$. Mendoza et al. [9] mentioned that UV-Vis absorption usually depends on the type and degree of substitution of the aromatic center of the molecules. In fact, polycarboxylate-based admixtures, in general, do not contain aromatic groups, it does not interfere in the UV-Vis absorption of CNT aqueous solutions.

Particle size distribution of CNT aqueous solutions was measured by dynamic light scattering (DLS) in a Zetasizer Nano (Malvern, UK), with a measuring range from $3.8 \mathrm{~nm}$ to $100 \mu \mathrm{m}$ and temperature of $25^{\circ} \mathrm{C}$. After the ultrasonication of CNT, the dispersions were diluted at 1:100 by volume.

FTIR analysis aimed to identify the interaction between CNT and SP. After the ultrasonication of CNT aqueous dispersions, samples were dried for $24 \mathrm{~h}$ at $70{ }^{\circ} \mathrm{C}$. The analysis was performed in $\mathrm{KBr}$ pellets in a Cary 600 Series FTIR Spectrometer, with an analysis range from 500 to $4000 \mathrm{~cm}^{-1}$, resolution of $8 \mathrm{~cm}^{-1}$, and 64 accumulations.

\subsection{Cementitious Composites Production and Characterization}

The CNT aqueous dispersions were added to $100 \mathrm{~g}$ of OPC in a solution/cement ratio of 0.40 by weight, and those were mixed for $3 \mathrm{~min}$ in a high-shear mixer (10,000 rpm).

Rheological analyses were performed in a Haake MARS III (Thermo Fisher Scientific, Waltham, MA, USA) rheometer with a four blades vane geometry (Ø16 $\mathrm{mm}$ and $22 \mathrm{~mm}$ of height). The tests were performed in samples with $25 \mathrm{~mL}$ at $23^{\circ} \mathrm{C}$ as the procedure described in [29]. The dynamic yield stress $\left(\tau_{0}\right)$ and equivalent viscosity $\left(\mu_{e q}\right)$ were calculated considering the decreasing part of the flow curve using the Herschel-Bulkley model in Equations (1) and (2) [30], respectively.

$$
\begin{gathered}
\tau=\tau_{0}+K \cdot \dot{g}^{n} \\
\mu_{e q}=\frac{3 K}{n+2} \cdot\left(\dot{g}_{\max }\right)^{n-1}
\end{gathered}
$$


where $\tau$ is the shear stress $(\mathrm{Pa}), \dot{g}$ is the shear rate $\left(\mathrm{s}^{-1}\right), \mathrm{K}$ is the consistency and $n$ is the pseudoplastic parameters, and $\dot{g}_{\text {max }}$ is the maximum shear rate. In addition, the mini slump test [31] was used to evaluate the flowability of the sample.

The hydration kinetics of cement pastes were evaluated by isothermal calorimetry in a TAM Air (TA Instruments) calorimeter. The test was carried out at a temperature of $23^{\circ} \mathrm{C}$ up to $48 \mathrm{~h}$.

The compressive strength of the CNT cementitious composites was evaluated at 1,7, and 28 days following ASTM C1231 [32]. Six cylindrical specimens (Ø20 mm $\times$ h $26 \mathrm{~mm})$ were cast for each cement paste. Analysis of variance (ANOVA) was conducted to verify whether the CNT content and ultrasonication amplitude evaluated have a significant influence on the compressive strength of cementitious composites.

X-ray diffraction (XRD) was conducted on a Miniflex II Desktop X-Ray Difractometer (Rigaku, Tokyo, Japan), with $30 \mathrm{kV} / 15 \mathrm{~mA}$, and CuK radiation $(\lambda=1.5418 \AA$ ). The analysis was performed from $5^{\circ}$ to $70^{\circ}(2 \theta)$, and with $0.02^{\circ} 2 \theta$ step size. Thermogravimetric analysis (TGA) was carried out using a SDT Q600 (TA Instruments) at a heating rate of $10^{\circ} \mathrm{C} / \mathrm{min}$ with a $\mathrm{N}_{2}$ flow of $50 \mathrm{~mL} / \mathrm{min}$.

For XRD and TGA analyses, cement hydration was stopped with isopropanol as described in [33]. After that, samples were ground until they passed a $45-\mu \mathrm{m}$-opening mesh.

\section{Results and Discussion}

3.1. Aqueous CNT Dispersions

3.1.1. UV-Vis Spectroscopy

UV-Vis spectroscopy was used to evaluate the quality of CNT dispersions in water. In aqueous solutions with low CNT concentrations, the absorbance obtained by the UV-Vis spectroscopy can be linearly related to the CNT concentration, as described by LambertBeer Law [34]. Thus, the higher the absorbance value, the greater the concentration of dispersed CNT. As seen in Figure 3, all the dispersions exhibit a characteristic peak in their UV-Vis spectrum at the wavelength of $253 \mathrm{~nm}$. Furthermore, with increasing ultrasonication amplitude, there was an increase in the CNT dispersion. This behavior is in agreement with previous studies [35,36]. Nevertheless, it is important to consider that ultrasonication may result in two opposite effects, one being the dispersion of CNT clusters and the other the fragmentation of individual CNT. Therefore, UV-Vis alone cannot determine the mean agglomerate size and cannot be used individually to determine the optimum ultrasonication energy for CNT dispersion [37]. Thus, DLS and FTIR tests were performed to complement the characterization of the CNT dispersions.

\subsubsection{Particle Size Distribution}

Figure 4 and Table 4 show the particle size distribution, average particle size, and polydispersity index (PDI) of CNT dispersions. The CNT solutions without ultrasonication were not stable, and it was not possible to perform the dynamic light scattering (DLS) test on these samples. Overall, CNT dispersions showed monomodal distribution. In addition, increasing the amplitude from $50 \%$ to $80 \%$ did not promote significant changes in the dispersion of CNT measured by DLS.

PDI is used to evaluate CNT dispersion quality. In general, PDI $>0.5$ is associated with poly disperse distributed samples [30]. Thus, ultrasonicated dispersions can be considered homogeneous. It should be stressed that DLS is an accurate technique for measuring the particle size of spherical particles. However, the aspect ratio and CNT agglomerates may affect the particle size results [38]. Reales and Toledo Filho [39] mentioned that the results obtained from this technique are representative of CNT agglomerates. This must be carefully considered when interpreting the results of particle size analysis. According to Chowdhury and Cui [40], the CNT dimensions cannot be directly correlated with the DLS results, since this technique is more suitable for analyzing spherical particles. Nonetheless, it may be used as an indication of agglomeration. 


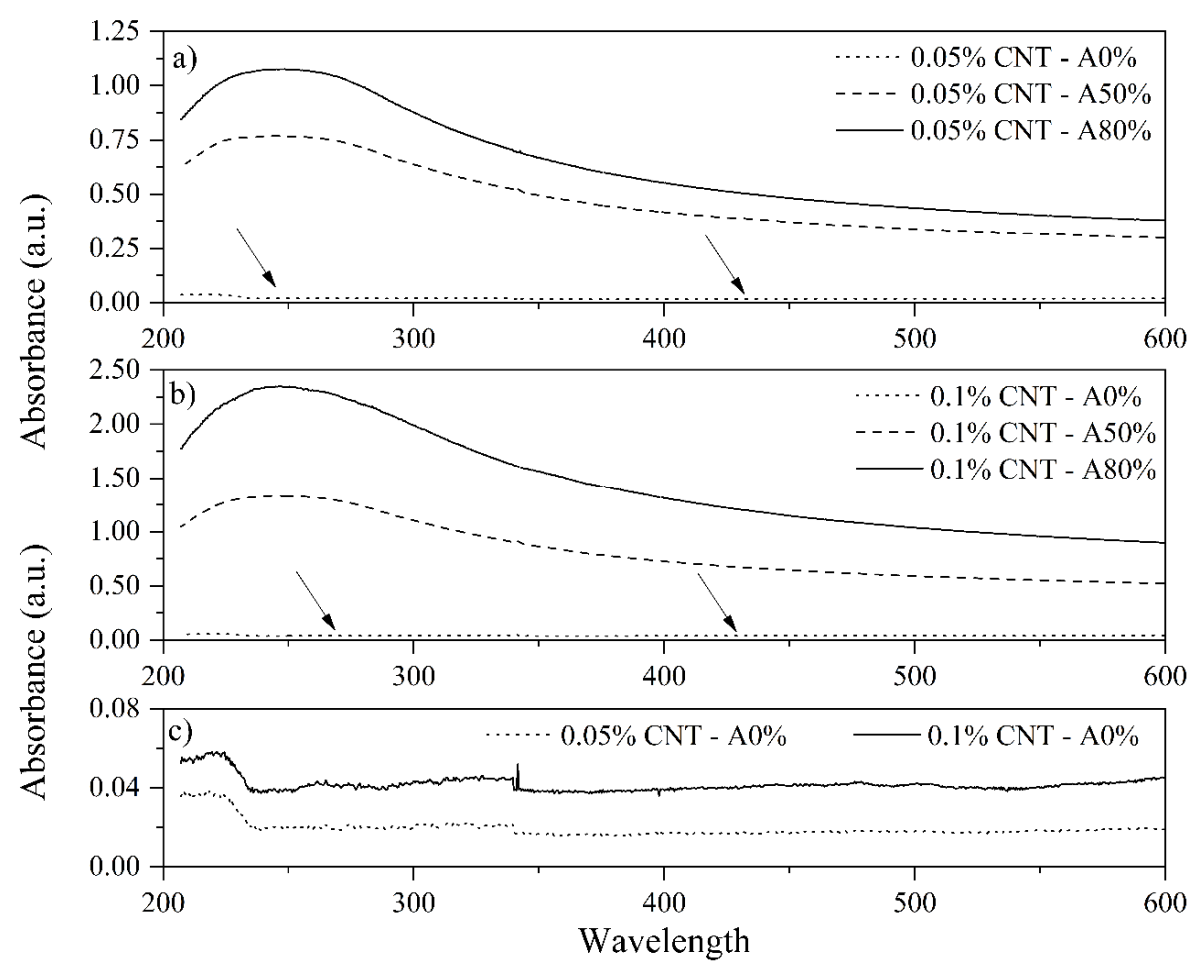

Figure 3. Influence of ultrasonication amplitude on UV-Vis absorption spectra of (a) $0.05 \%$ CNT; (b) $0.1 \%$ CNT dispersions and (c) amplification of $0.05 \%$ CNT-A0\% and $0.1 \% \mathrm{CNT}-\mathrm{A} 0 \%$.
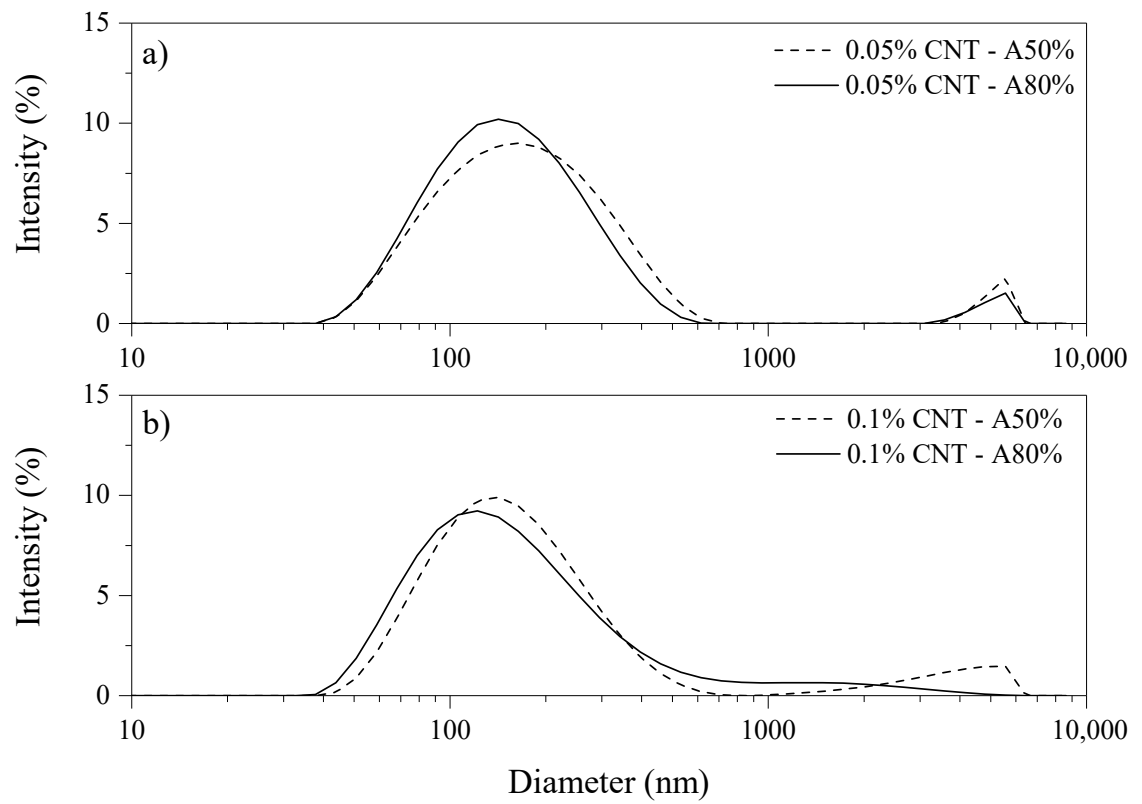

Figure 4. Influence of ultrasonication amplitude on particle size distribution of (a) $0.05 \% \mathrm{CNT}$ and (b) $0.1 \%$ CNT dispersions.

Table 4. Average particle size and polydispersity index (PDI) of CNT dispersions.

\begin{tabular}{ccc}
\hline CNT Dispersions & Average Particle Size (nm) & PDI \\
\hline $0.05 \%$ CNT-A $50 \%$ & 158.1 & 0.381 \\
$0.05 \%$ CNT-A $80 \%$ & 138.0 & 0.322 \\
$0.1 \%$ CNT-A $50 \%$ & 143.2 & 0.355 \\
$0.1 \%$ CNT-A $80 \%$ & 130.1 & 0.275 \\
\hline
\end{tabular}




\subsubsection{FTIR}

The spectra of $0.05 \% \mathrm{CNT}$ and $0.1 \%$ CNT aqueous dispersions are shown in Figures 5 and 6, respectively. New absorption bands in CNT dispersions appeared at $2920 \mathrm{~cm}^{-1}$, which are attributed to the stretching vibration of $-\mathrm{CH}_{2}$ [41]. This is attributed to SP molecules [41]. The appearance of these bands is more evident in dispersions with $0.05 \%$ CNT since they have a higher CNT:SP ratio compared with dispersions with $0.1 \%$ CNT. It can also be observed that, in CNT dispersions submitted to ultrasonication, the bands assigned to $-\mathrm{CH}_{2}$ were attenuated. This may be an indication that ultrasonication promotes changes in the SP molecules. Similarly, the results obtained by $\mathrm{Hu}$ et al. [41] also indicated that the ultrasonication of the polycarboxylate admixture causes an attenuation of the band attributed to $-\mathrm{CH}_{2}$. In this context, the studied conducted by Dehghani et al. [42] indicated that the ultrasonication can be used for degradation of surfactants in aqueous solutions. The longer the ultrasonication time and the lower the concentration of surfactant, the greater the degree of degradation. Thus, the effect of ultrasonication on SP admixtures should be further investigated, especially for long periods. It can also be seen in Figures 5 and 6 that, in ultrasonicated CNT dispersions, there was a reduction in the band at $1629 \mathrm{~cm}^{-1}$, attributed to the $C=C$ stretching of CNT graphene structure [43-49]. These results may indicate that the ultrasonication have caused damage to the CNT structure [50]. Previous studies also indicated that the ultrasonication can damage the CNTs [2,12].
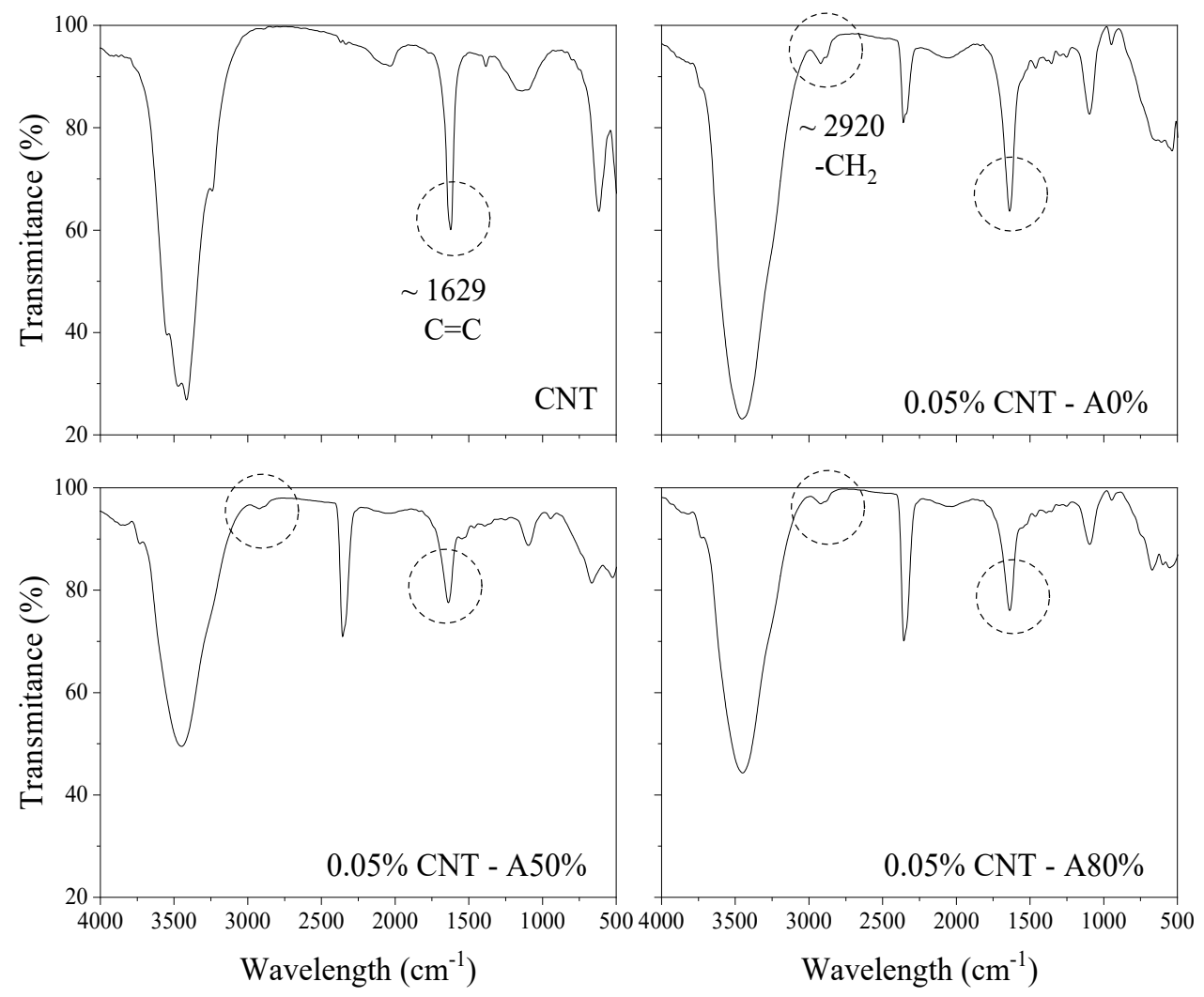

Figure 5. FTIR spectra of polycarboxylate-based superplasticizer and 0.05\% CNT dispersions. 

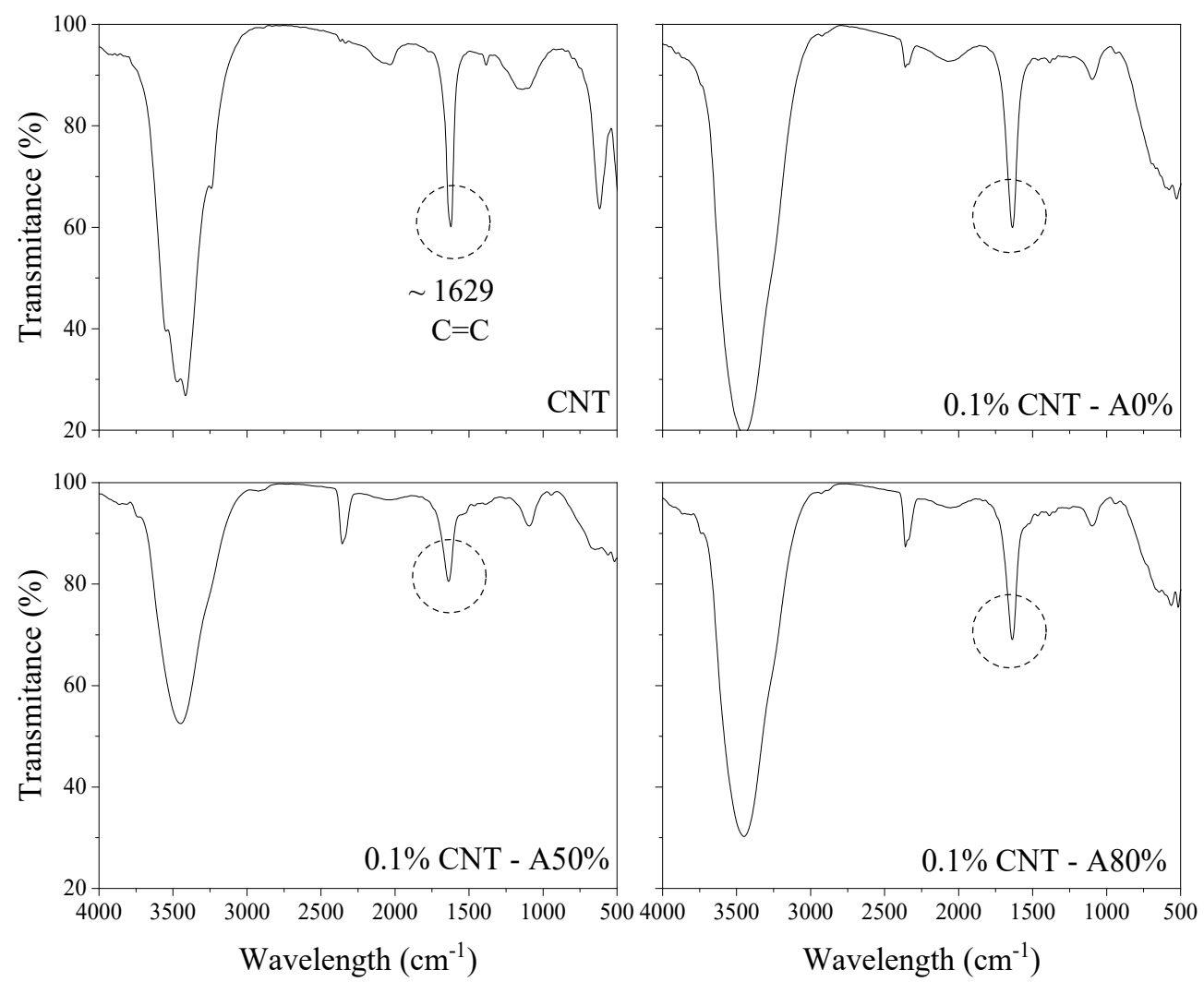

Figure 6. FTIR spectra of polycarboxylate-based superplasticizer and $0.1 \%$ CNT dispersions.

\subsection{Cementitious Composite Characterization}

\subsubsection{Rheological Tests}

Figures 7 and 8 show the rheological results of cement pastes. The increase of CNT content and amplitude of ultrasonication gradually increased the static and dynamic yield stress and decreased the mini slump of the pastes. The addition of nanomaterials changes the rheological properties of cement pastes and severely reduces their workability. According to Jiang et al. [51], the high specific surface area of CNT is the main reason affecting the rheology of cement pastes. This is because the large surface area of nanomaterial demands more water to wet their surface, consequently reducing the free water available for lubrication at a given $\mathrm{w} / \mathrm{c}$ ratio [52]. Besides that, CNT can interact with SP admixtures, facilitating their dispersion and reducing the amounts of SP available to interact with the cement grains [53]. This trend may contribute to the increase in viscosity and yield stress of CNT cementitious composites compared with plain cement paste.

Regarding the effect of the ultrasonication amplitude, a higher ultrasonication energy promoted a better CNT dispersion (Seen in Section 3.1), which results in a greater surface area available for SP adsorption, and consequently, less free SP to improve the workability of the cement paste [10]. Studies evaluating the rheological properties of cementitious composites with CNT are scarce $[51,53,54]$. One of the few studies that show the detailed rheological characterization of CNT-reinforced cementitious pastes is that from Andrade Neto et al. [53], which also found a progressive increase in yield stress with the increase of CNT up to $0.10 \%$. Additionally, the increase in yield stress caused by the incorporation of other nanomaterials has already been reported in the literature [55-57]. Mendoza Reales et al. [56] observed that incorporating $1 \%$ NS in cement paste increased its static $\tau_{0}$ from 30 to $260 \mathrm{~Pa}$. Hou et al. [57] observed that the incorporation of $2.25 \%$ of colloidal NS increased the yield stress of paste from about 49 to $71 \mathrm{~Pa}$ (i.e., by $45 \%$ ). Andrade et al. [58] reported that cement paste with 3\% NS required 6 times more SP than plain cement paste did to reach a given sample spread related to the yield stress. In 
general, these authors attributed the yield stress increases to the extremely high specific surface area of the nanomaterials.
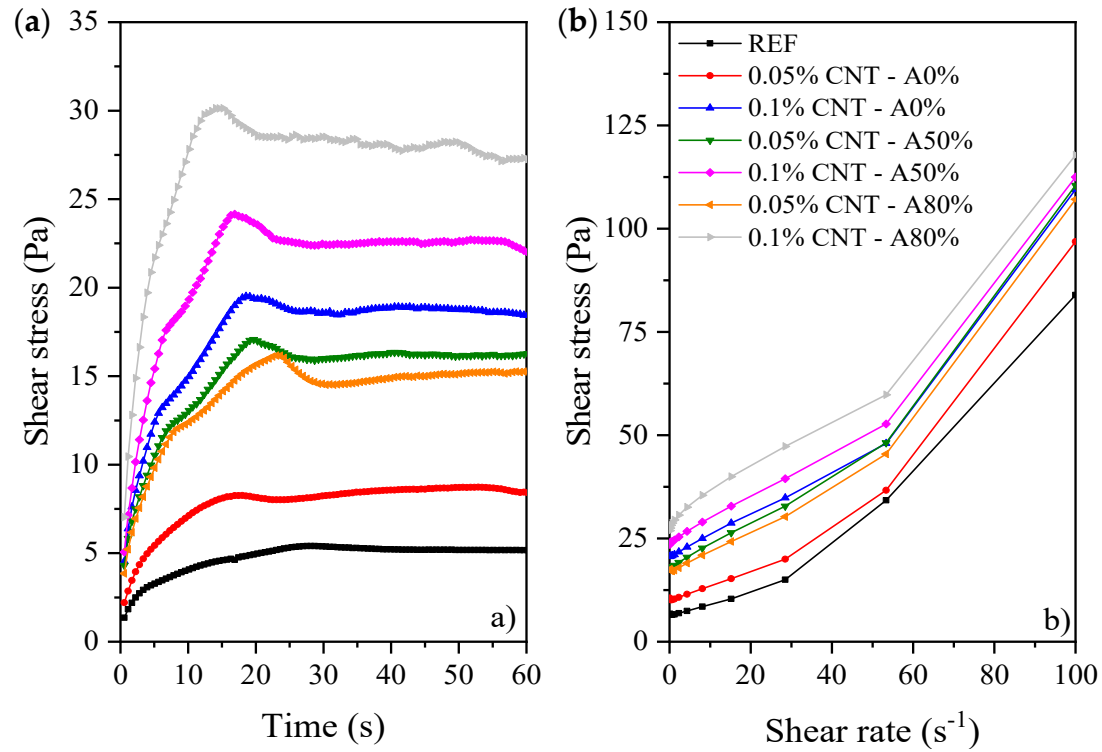

Figure 7. Curves of rheological tests: (a) static yield stress determination, and (b) flow curves of cement pastes.
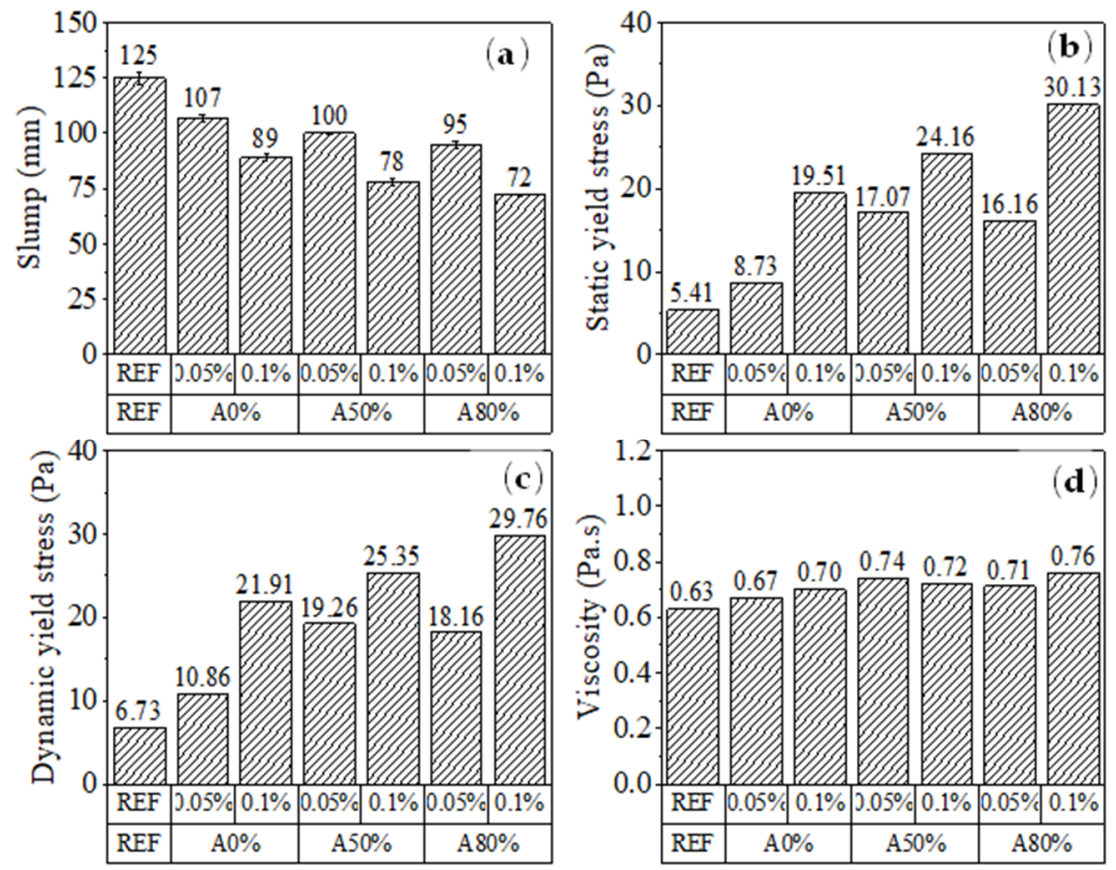

Figure 8. Rheological parameters of CNT cementitious composites: (a) slump; (b) static and (c) dynamic yield stresses, and (d) viscosity.

\subsubsection{Isothermal Calorimetry}

The heat flow and cumulative heat results of cement pastes are presented in Figure 9. Table 5 summarizes isothermal calorimetry results. Four steps were identified in the heat flow curves: (1) initial period; (2) induction period; (3) accelerating period; and (4) decelerating period. The initial period is related with the dissolution of cement phases. In the induction period, the initially rapid rate of reaction decreases down to remain a low rate, and mainly ionic chances occur. In the accelerating period, the precipitation of calcium silicate hydrates $(\mathrm{C}-\mathrm{S}-\mathrm{H})$ and $\mathrm{Ca}(\mathrm{OH})_{2}$ occurs. Finally, the decelerating period is 
associated with the gradual reduction of the reaction rate [59]. The isothermal calorimetry results also indicated that the conversion of ettringite to AFm phases did not occur for up to $50 \mathrm{~h}$. Conversion can be identified by a shoulder peak in the heat flow curve [60]. According to Bullard et al. [60], the AFm formation usually occurs after $50 \mathrm{~h}$ for cement with a $3.5 \% \mathrm{SO}_{3}$, which is a usual $\mathrm{C}_{3} \mathrm{~A}$-to-sulfate ratio in modern cement. The isothermal calorimetry results are consistent with the XRD patterns of the cement pastes with 1 day of hydration further discussed, which also did not indicate the presence of AFm phases.
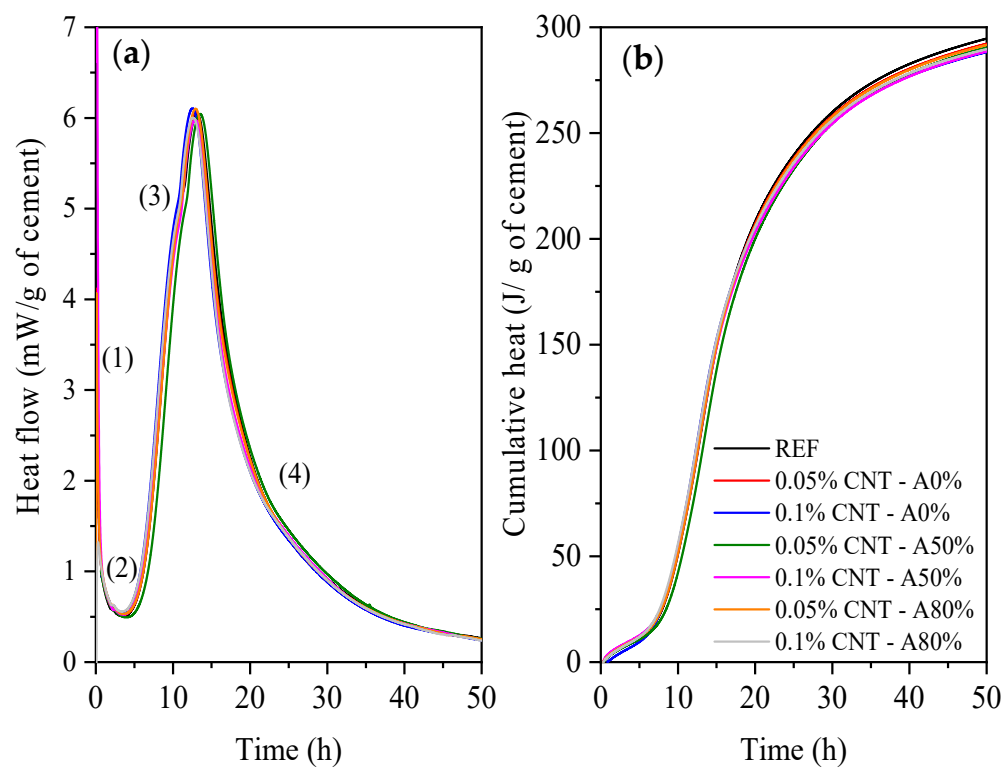

Figure 9. Heat flow (a) and cumulative heat (b) curves of cement pastes.

Table 5. Isothermal calorimetry results.

\begin{tabular}{ccccc}
\hline Cement Paste & $\begin{array}{c}\text { Main Heat Flow Peak } \\
(\mathbf{m W} / \mathbf{g})\end{array}$ & $\begin{array}{c}\text { Main Heat Flow Peak } \\
\text { Time (hh:mm) }\end{array}$ & $\begin{array}{c}\mathbf{2 4} \text { h Cumulative Heat } \\
\text { (J/g) }\end{array}$ & $\begin{array}{c}\text { 48 h Cumulative Heat } \\
(\mathbf{J} / \mathbf{g})\end{array}$ \\
\hline REF & 6.05 & $13: 08$ & 234.4 & 292.6 \\
$0.05 \%$ CNT-A0\% & 6.08 & $12: 57$ & 232.9 & 290.3 \\
$0.1 \%$ CNT-A0\% & 6.11 & $12: 30$ & 230.5 & 286.4 \\
$0.05 \%$ CNT-A50\% & 6.05 & $13: 30$ & 227.5 & 288.5 \\
$0.1 \%$ CNT-A50\% & 5.98 & $12: 50$ & 228.7 & 286.7 \\
$0.05 \%$ CNT-A80\% & 6.10 & $12: 54$ & 232.3 & 289.7 \\
$0.1 \%$ CNT-A80\% & 6.00 & $12: 36$ & 230.9 & 287.8 \\
\hline
\end{tabular}

According to Macleod et al. [61], the hydration kinetics of CNT nanocomposites by isothermal calorimetry has not been widely investigated. As pointed out by Andrade Neto et al. [53], the results regarding the effect of CNT on cement hydration are divergent. In general, CNT accelerates cement hydration [62,63]. In turn, some studies have reported hydration delays $[64,65]$, which are usually attributed to either the material used for CNT dispersion like surfactant or SP admixtures [53], or else to an inefficient dispersion.

CNT incorporation did not significantly change the main heat flow peak, although slightly anticipated its occurrence (by up to $4 \%$ ), except for $0.05 \%$ CNT-A50\%. The CNT used were functionalized with carboxyl groups and can absorb mixing water and reduce the effective $\mathrm{w} / \mathrm{c}$ ratio due to their hydrophilic behavior [66,67], which results in increasing the concentration of alkaline ions, contributing to the acceleration of initial hydration reactions [68]. Nonetheless, all these variations were of up to $0.63 \mathrm{~h}$ compared with control pastes (REF).

It is stressed that the standard deviation associated with isothermal calorimetry repeatability is up to $7 \mathrm{~J} / \mathrm{g}$ [68]. Thus, the $24 \mathrm{~h}$ and $48 \mathrm{~h}$ cumulative heat of all cement pastes evaluated are within this range and, in this way, can be attributed to the variability of 
the isothermal calorimetry test. Therefore, the obtained results indicated that the CNT incorporation did not promote significant changes in the hydration kinetics of OPC.

\subsubsection{Compressive Strength}

The average compressive strength values of the cement pastes are presented in Figure 10. Table 6 summarizes the ANOVA results of compressive strength values. The tree factors evaluated (CNT content, amplitude, and hydration time) had a significant influence on the compressive strength, as well as all the interactions between the factors, except for $\mathrm{A} \times \mathrm{B}$. At 1 day, $0.05 \mathrm{CNT}-\mathrm{A} 0 \%$ presented a $13.2 \%$ increase in compressive strength compared with the plain cement paste (REF). The higher improvements with CNT incorporation were obtained at 7 days. In relation to the plain cement paste (REF), these increases were of $10.6 \%$ (0.05CNT-A $0 \%), 15.8 \%(0.05 \mathrm{CNT}-\mathrm{A} 50 \%)$, and $13.1 \%(0.05 \mathrm{CNT}-\mathrm{A} 80 \%)$. At 28 days, these values were $13.8 \%, 4.9 \%$ and $12.5 \%$, respectively.

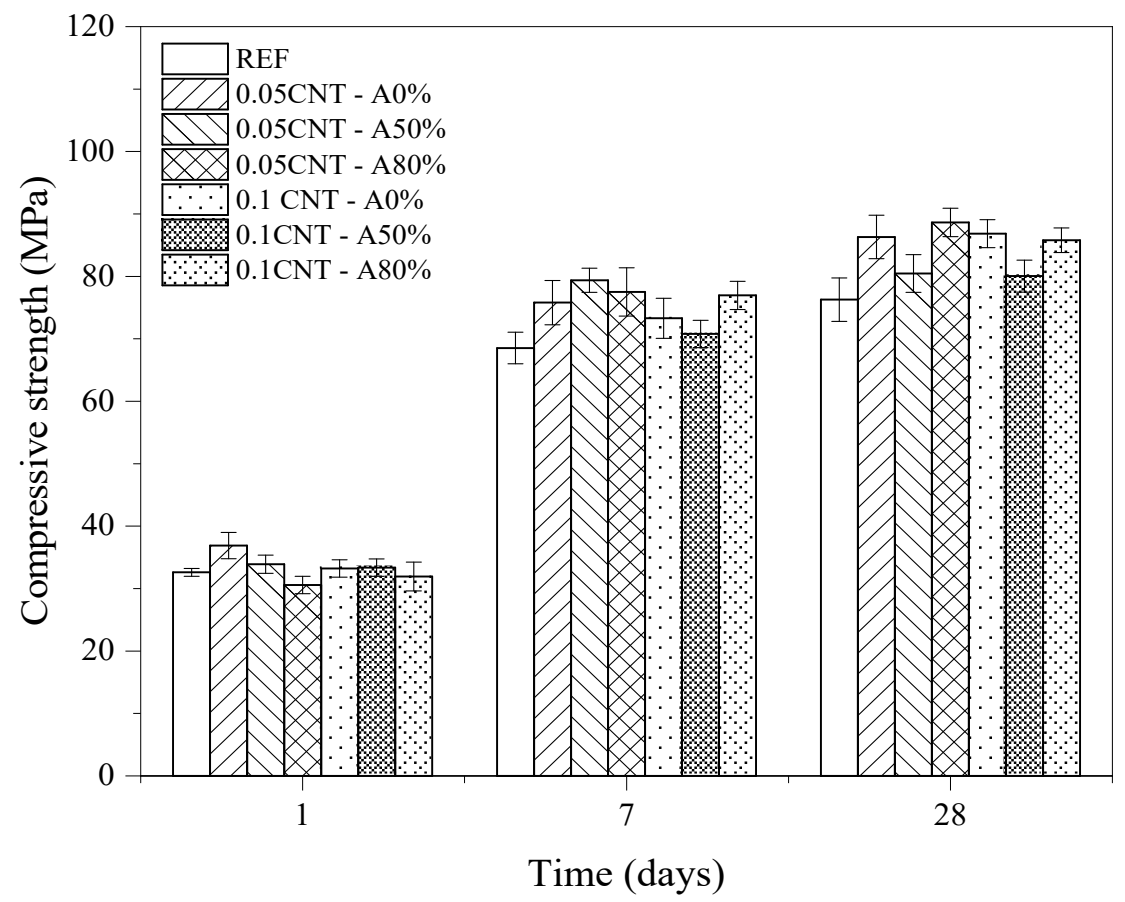

Figure 10. Compressive strength at 1,7 and 28 days of the cementitious composites.

Table 6. Three-way ANOVA of compressive strength results.

\begin{tabular}{cccccc}
\hline Factor & $\begin{array}{c}\text { Sum of Squares } \\
\text { (SS) }\end{array}$ & $\begin{array}{c}\text { Degrees of } \\
\text { Freedom (DF) }\end{array}$ & $\begin{array}{c}\text { Mean Square } \\
\text { (MS) }\end{array}$ & $p$ Value & Sig. ${ }^{\text {a }}$ \\
\hline CNT content (A) & 157.249 & 1 & 157.249 & $5.84 \times 10^{-7}$ & $\mathrm{~S}$ \\
Amplitude (B) & 203.390 & 2 & 101.695 & $1.74 \times 10^{-7}$ & $\mathrm{~S}$ \\
Time (C) & $45,132.668$ & 2 & $22,566.334$ & 0 & $\mathrm{~S}$ \\
A $\times$ B & 13.668 & 2 & 6.834 & 0.27857 & $\mathrm{NS}$ \\
A $\times$ C & 121.266 & 2 & 60.633 & $4.35 \times 10^{-5}$ & $\mathrm{~S}$ \\
B $\times$ C & 418.700 & 4 & 104.675 & $3.65 \times 10^{-11}$ & $\mathrm{~S}$ \\
A $\times$ B $\times$ C & 106.011 & 4 & 26.503 & 0.00119 & $\mathrm{~S}$ \\
Error & 388.891 & 74 & 5.255 & - & - \\
Total & $46,541.843$ & 91 & - & - & - \\
\hline
\end{tabular}

a S-Significant, NS-Not significant.

To complement the analysis of compressive strength results, Tukey's multiple comparison test was performed. This test was used because is widely applied and allows to determine if there is a difference between the mean of all pairs of the study [69]. The results are shown in Table 7 . The optimum CNT content was $0.05 \%$ by cement weight 
since the addition of $0.1 \%$ CNT generally led to lower compressive results. This content is close to the optimum level of $0.075 \%$ reported by Andrade Neto et al. [53]. Additionally, there was no significant difference between the amplitudes $\mathrm{A} 0 \%$ and $\mathrm{A} 80 \%$ results, while the comparisons between $\mathrm{A} 0 \%$ and $\mathrm{A} 50 \%, \mathrm{~A} 50 \%$ and $\mathrm{A} 80 \%$ had significant differences. These results indicate that, in general, the use of an amplitude of $50 \%$ in the ultrasonication process for CNT dispersion is not effective to improve the compressive strength results of cement pastes. In addition, since there are no significant statistic differences between $\mathrm{A} 0 \%$ and $\mathrm{A} 80 \%$, it is concluded that the addition of CNT without ultrasonication in cement pastes was the best option from the point of view of compressive strength. Indeed, it led to the same mechanical performance as the pastes with CNT dispersed by ultrasonication with amplitude of $80 \%$, without the dispersion step of CNT for incorporation in cementitious composites. It is worth highlighting that the unsonicated mixes (A0\%) also had the best rheological performance among the CNT-containing mixes, reinforcing that ultrasonication may be avoided in functionalized CNT. This is because unsonicated mixed presented a smaller increase in the yield stress and viscosity of the cement pastes. This can be beneficial, since significant increases in yield stress and viscosity can reduce the flowability of cementitious composites. This can make it difficult for air bubbles to escape from the fresh mix, consequently increasing the porosity of the matrix [70].

Table 7. Tukey's multiple comparison test of compressive strength results.

\begin{tabular}{ccccccc}
\hline Factor & Levels & $\begin{array}{c}\text { Mean } \\
\text { Difference }\end{array}$ & $\begin{array}{c}\text { Standard Error of } \\
\text { the Mean (SEM) }\end{array}$ & q Value & Prob. & Sig. ${ }^{\text {a }}$ \\
\hline CNT content & $0.05-0.1 \%$ & 2.825 & 0.463 & 8.625 & $8.52 \times 10^{-8}$ & $\mathrm{~S}$ \\
Amplitude & A0-A50\% & 2.670 & 0.521 & 7.236 & $7.00 \times 10^{-6}$ & S \\
Amplitude & A0-A80\% & 1.008 & 0.599 & 2.378 & 0.219 & NS \\
Amplitude & A50-A80\% & 3.679 & 0.577 & 9.004 & $1.95 \times 10^{-8}$ & S \\
\hline \multicolumn{2}{c}{ a S-Significant, NS-Not significant. }
\end{tabular}

Increases in compressive strength of cement pastes with CNT incorporation can generally be explained by the heterogeneous nucleation effect [39,53]. Additionally, the CNT bridging effect of hydrates and nano-cracks can provide mechanical reinforcement [71]. Similarly, for Chen and Akono [72], CNT enhanced the mechanical properties of cement pastes by high-density $\mathrm{C}-\mathrm{S}-\mathrm{H}$ and $\mathrm{Ca}(\mathrm{OH})_{2}$ formation, reducing the porosity of the matrix.

Regarding the application of ultrasonication amplitudes of $50 \%$ and $80 \%$ for CNT dispersion, the energy provided may damage CNT and SP molecules, as previously discussed. Consequently, CNT may improve the mechanical performance of composite only by filling effect, while the nano-reinforcement (i.e., bridging effect) is no longer efficient due to CNT deterioration. According to Alatawna et al. [73], the ultrasonication of functionalized CNT promotes the shortening of CNT since nanotubes tend to break in defects induced by functional groups on the surface of the nanomaterial. Thus, the shorter CNT are less effective in enhancing the mechanical properties of composites.

\subsubsection{Microstructure}

Figures 11-13 show the XRD patterns of hydrated cement pastes at 1, 7 and 28 curing days, respectively. At 1 day of hydration, the main crystalline phases found were those from anhydrous cement (alite, ferrite, calcite, and periclase), in addition to portlandite and ettringite formed by the hydration reactions. A diffuse hump around $25-40^{\circ} 2 \theta$ can already be found at this age, which corresponds to the amorphous (or nano-crystalline) contribution of C-S-H [29]. No AFm phases were found at this age, since the only reflection found up to $2 \theta=12^{\circ}$ was that associated with ettringite (at around $9.0^{\circ} 2 \theta$ ). This corroborates with the isothermal calorimetry results, which showed the absence of the typical broad peak of heat release at the deceleration period related with the formation of AFm up to $50 \mathrm{~h}$. At 7 days, a considerable decrease in alite peaks (mainly at $2 \theta=29.3,32.2,32.5$, and $34.3^{\circ}$ ) were observed for all the samples, and this is associated with the progress in cement hydration. 
At this age, a broad peak at $2 \theta=11.4^{\circ}$ was observed, associated with the formation of Afm phases [74] due to the presence of calcite in the cement used, as exemplified in Figure 14 and confirmed latter by the TGA results. The same overall trend was observed in the XRD patterns of the samples with 28 days of hydration.

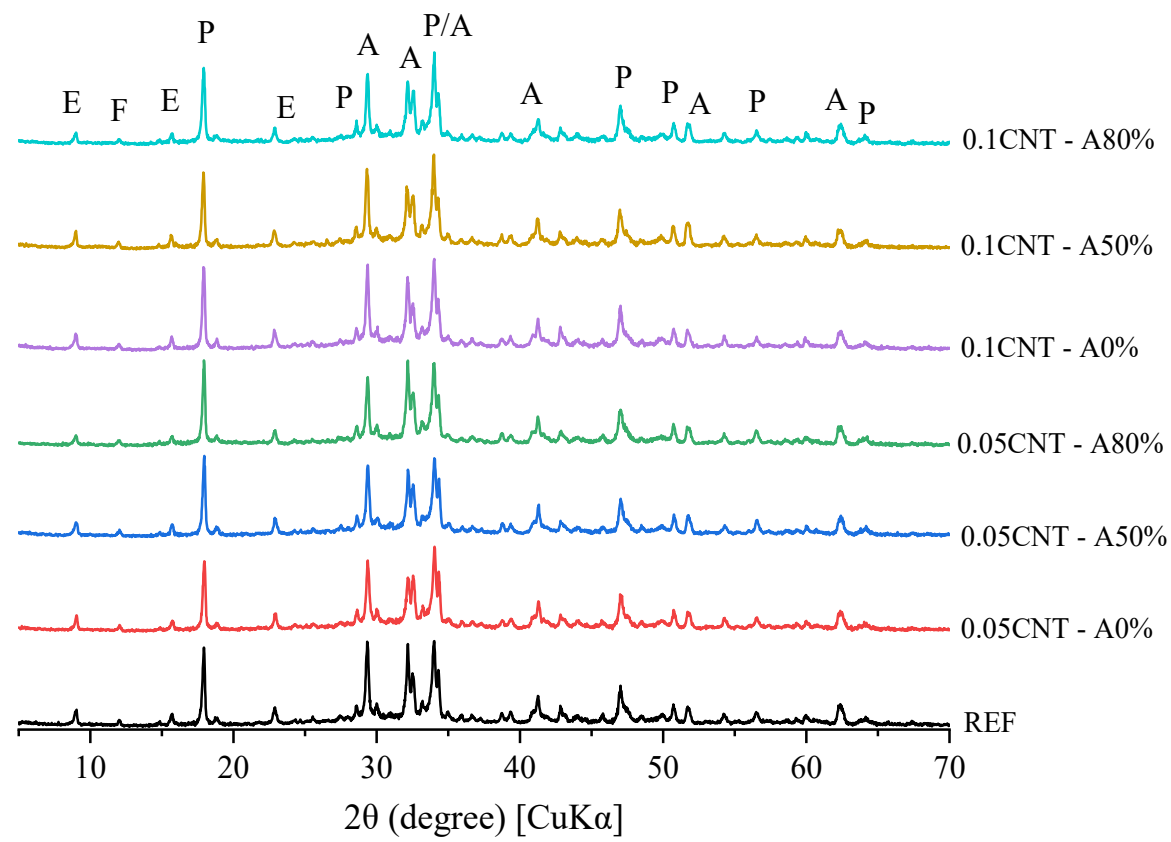

Figure 11. XRD patterns of cement pastes at 1 day of hydration (A-alite; E-ettringite; F-ferrite; $\mathrm{P}$-portlandite).

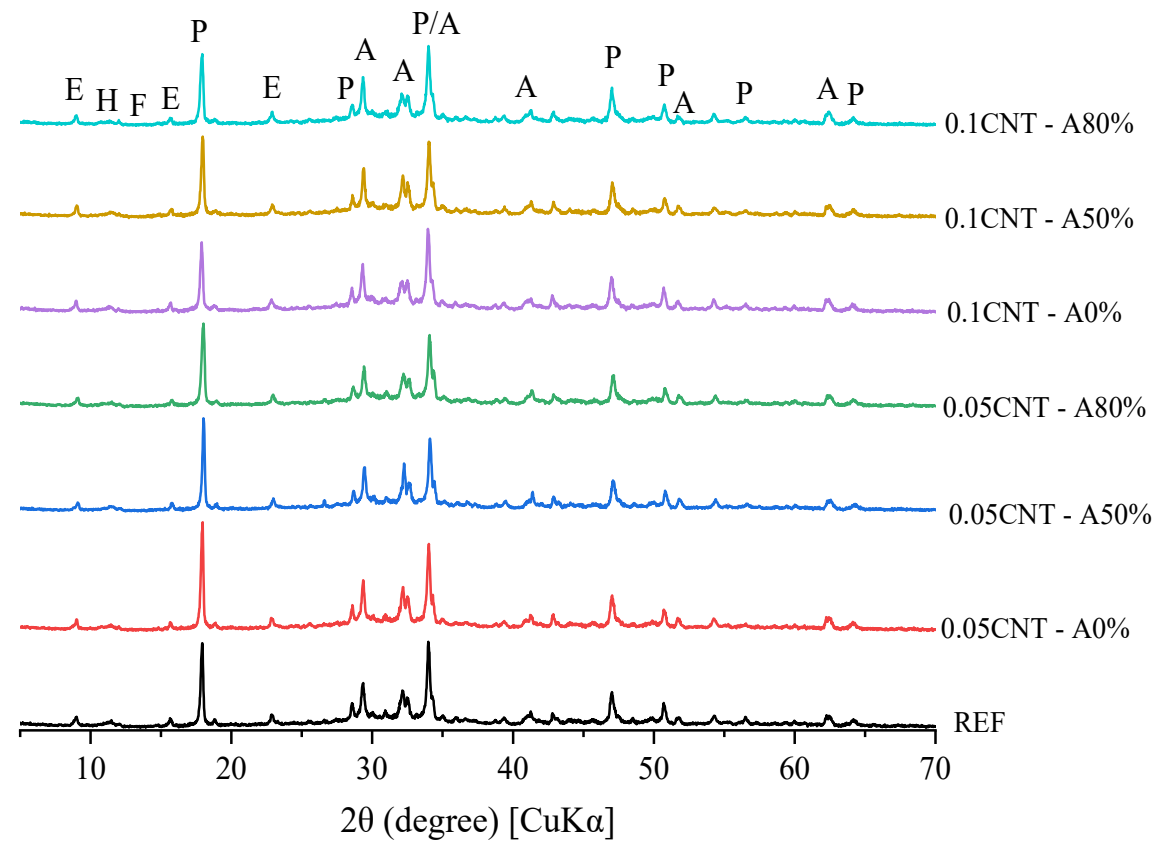

Figure 12. XRD patterns of cement pastes at 7 days of hydration (A—alite; E-ettringite; F-ferrite; $\mathrm{H}$-hemicarbonate; $\mathrm{P}$ - portlandite). 


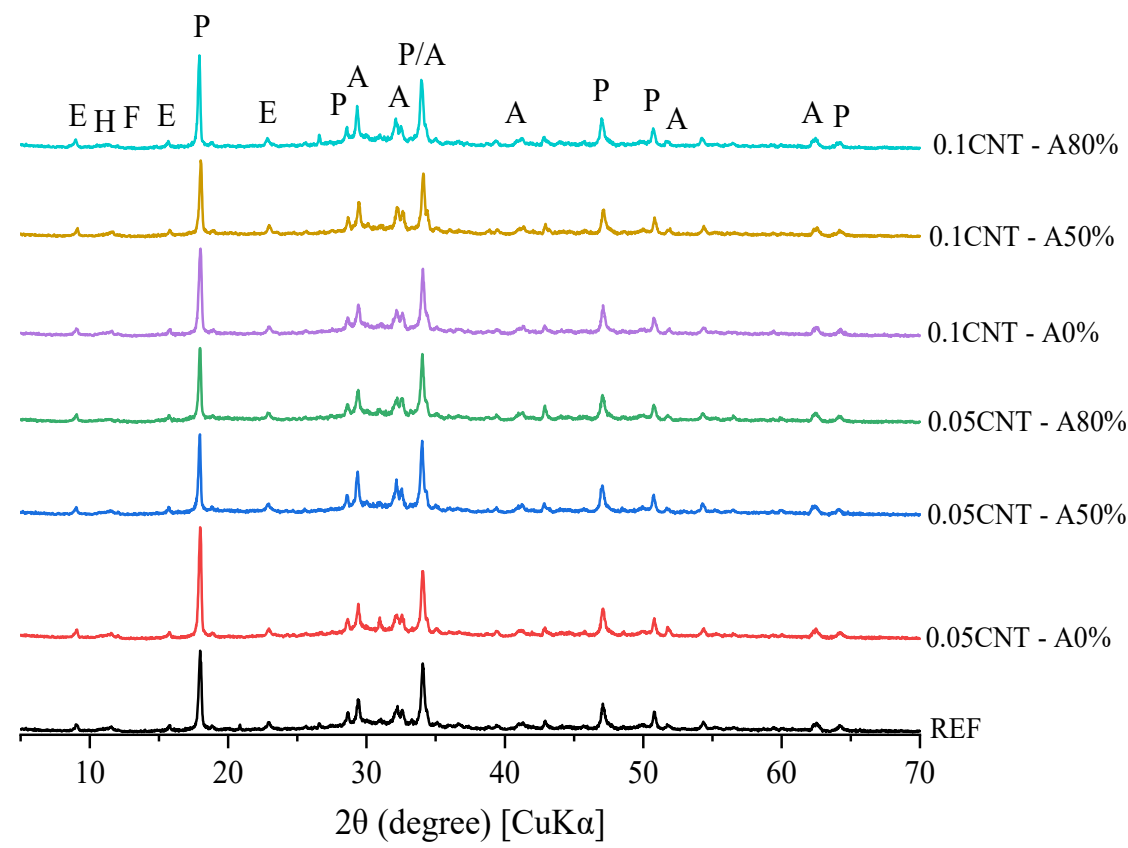

Figure 13. XRD patterns of cement pastes at 28 days of hydration (A-alite; $\mathrm{E}$ - ettringite; $\mathrm{F}$-ferrite; $\mathrm{H}$-hemicarbonate; $\mathrm{P}$ - portlandite).
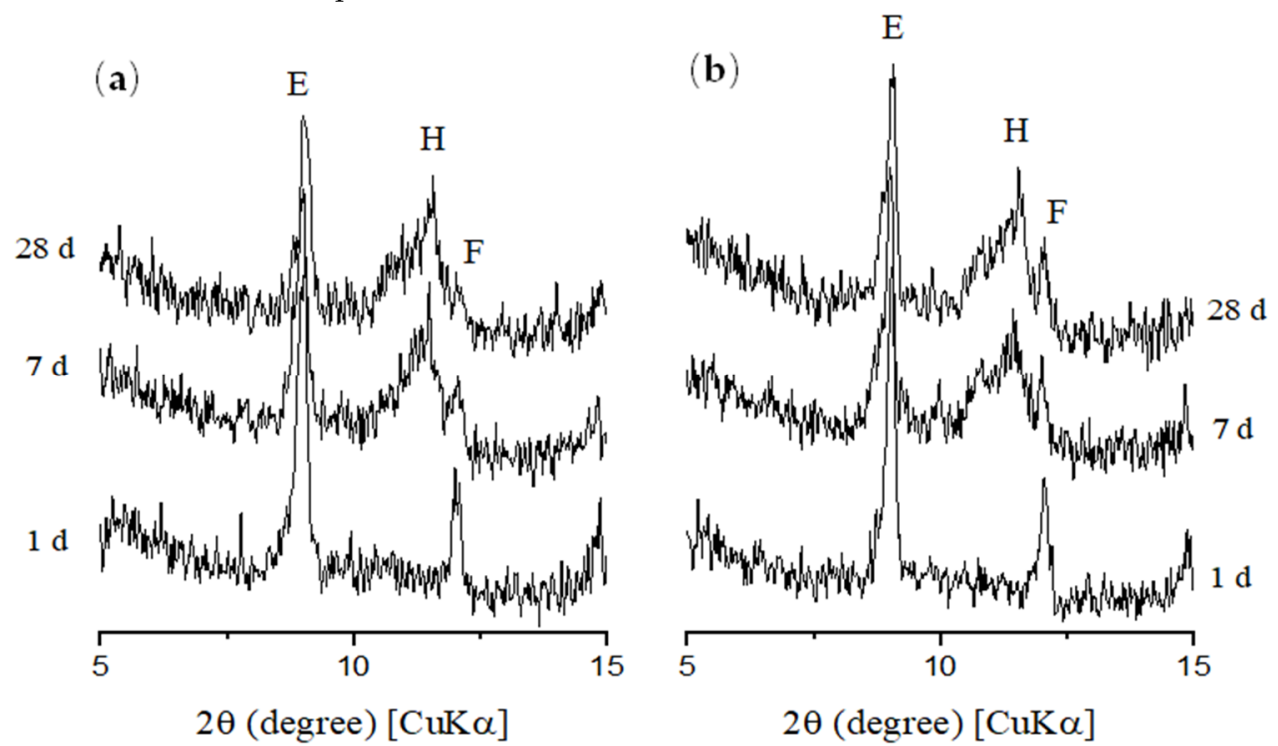

Figure 14. XRD patterns of (a) REF and (b) $0.05 \mathrm{CNT}-\mathrm{A} 0 \%$ at 1,7 and 28 days (E-ettringite; $\mathrm{F}$-ferrite; $\mathrm{H}$-hemicarbonate).

The XRD patterns of CNT-reinforced pastes were equivalent to that of plain cement paste (REF) at the respective hydration times, regardless of the CNT content and dispersion i.e., with and without ultrasonication. This indicates that that no new phases were formed due to the presence of CNT in the matrix during cement hydration as expected. This also indicates that the incorporation of CNT, either ultrasonicated or not, did not result in significant differences in cement hydration. Even though the extremely high surface area of CNT can provide extra surface for the nucleation and growth of hydrated products and therefore enhance the cement hydration [75], this nanomaterial was added at up to $0.1 \%$ by cement weight. This content may not be enough to result in significant changes in hydration. Similar results were reported by Andrade Neto et al. [53], who added up to $0.10 \%$ CNT in cement paste and found equivalent hydration degrees at 28 days, regardless of the CNT presence and content. One can note differences in the 001 reflection of portlandite (at $18.0^{\circ}$ $2 \theta$ ) when comparing samples at a given age e.g., $0.05 \% \mathrm{CNT}-\mathrm{A} 0 \%$ vs. $0.1 \mathrm{CNT}-\mathrm{A} 0 \%$ 
at 7 days, and therefore expect different hydration degrees. However, the 101 reflection of portlandite at $2 \theta=34.1^{\circ}$ was equivalent for all the mixes at a given age, confirming the similar hydration degrees of the samples. This is explained by the flat-like hexagonal shape of portlandite crystals, which can face severe preferred orientation during sample preparation in powder XRD. This is discussed in detail in [76].

Finally, these results suggest that the compressive strength improvements promoted by CNT incorporation (seen in Section 3.2.3) were essentially mechanical, i.e., the so-called bridging effect, rather than the further formation of hydrated products.

Figure 15 shows the TGA curves of the pastes at 28 days of hydration and the insets show the DTG of the curves at specific regions. The large peak at $50-200{ }^{\circ} \mathrm{C}$ in DTG is associated with ettringite decomposition (pointed as Ett). A shoulder peak was also identified in this region at $150-200{ }^{\circ} \mathrm{C}$, which is associated with the decomposition of aluminate phases (pointed as AFm), in line with the XRD results at this age. It is stressed that the hydration was stopped through solvent exchange (see Section 2.4), so no free water was found in TGA. Finally, the peak at $400-550{ }^{\circ} \mathrm{C}$ is assigned to the portlandite (i.e., $\left.\mathrm{Ca}(\mathrm{OH})_{2}\right)$ decomposition. Slight vertical displacements were observed in this region for the $0.05 \%$ CNT-A $0 \%$ and - A $80 \%$ DTG curves compared with the plain cement paste (REF) and CNT-A50\% curves, which can be associated with the baseline displacement. Nonetheless, the relative height of the decomposition peaks was similar for all the samples.

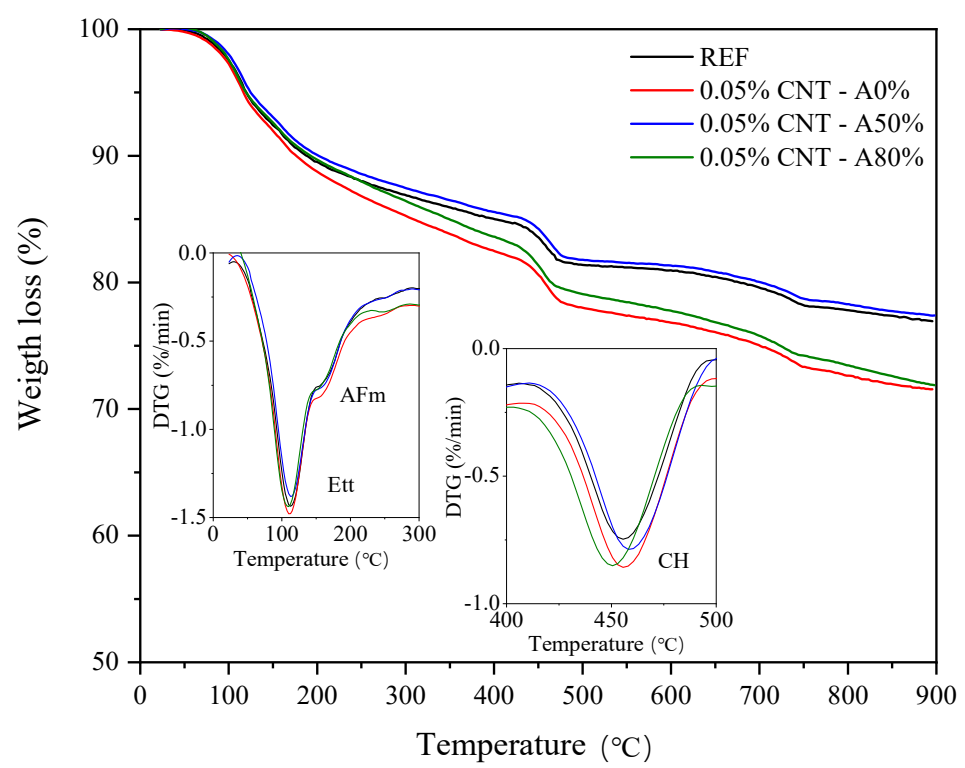

Figure 15. TGA and DTG curves of the pastes at 28 days of hydration. Ett: ettringite; AFm: aluminate phases; $\mathrm{CH}$ : calcium hydroxide.

Regarding the incorporation of CNT, DTG curves indicated equivalent contents of ettringite, monocarbonate and portlandite for all the pastes, at 28 days of hydration. These results suggest that CNT did not significantly influence the cement hydration at this age, which in line with the XRD results and corroborates with the hypothesis that CNT improved the mechanical strength of the composites essentially by mechanical reinforcement.

\section{Conclusions}

This work investigated the influence of ultrasonication of functionalized carbon nanotubes (CNT) with different amplitudes on the rheology, hydration kinetics, compressive strength, and microstructure of Portland cement pastes. The increase in ultrasonication energy promoted a better dispersion of CNT in aqueous solution, evidenced by UV-Vis spectroscopy and DLS results. However, FTIR results from CNT plus superplasticizer (SP) solutions indicated that ultrasonication may have damaged both SP molecules and CNT. Nevertheless, additional characterization is needed to fully understand this phenomenon. 
Rheological tests evidenced that the increase in CNT content and ultrasonication amplitude gradually increased the static and dynamic yield stress, while decreased the mini slump spread of the paste. The higher surface area available in the ultrasonicated CNT systems can explain this trend.

CNT incorporation did not promote significant changes in the hydration kinetics of cement up to $50 \mathrm{~h}$, with comparable heat flow and cumulative heat curves regardless of the CNT presence, content and ultrasonication.

Compressive strength results indicated that the optimum CNT content was $0.05 \%$ by cement weight, leading to strength increases of up to $15.8 \%$ compared with plain paste. The dispersion of CNT by ultrasonication with amplitudes of $50 \%$ and $80 \%$ did not contribute to increasing the compressive strengths compared with CNT without ultrasonication.

XRD and TGA results indicated that CNT incorporation did not significantly affect the formation of hydrated products regardless of the CNT content and ultrasonication energy, corroborating the calorimetry results. These results suggest that the compressive strength improvements promoted by CNT were essentially mechanical.

Overall, ultrasonication of functionalized CNT is not efficient in improving the fresh and hardened performance of cementitious composites. In this context, the contribution of this work is extremely relevant from the point of view of the practical application of the functionalized CNT. This is because the results indicated that this type of CNT does not need to be dispersed by ultrasonication to improve the mechanical performance of cementitious composites. This is interesting since a limiting factor for the large-scale application of nanomaterials is precisely related to this dispersion step.

Author Contributions: Conceptualization, L.S.; methodology, L.S., G.L. and A.R.; formal analysis, L.S., A.R., G.L. and P.d.M.; investigation, L.S., G.L. and A.R.; resources, P.G.; data curation, L.S. and P.d.M.; writing—original draft preparation, L.S., A.R., G.L. and P.d.M.; writing—review and editing, P.G., A.R.G.d.A. and S.N.M.; supervision, P.G.; funding acquisition, P.G., A.R.G.d.A. and S.N.M. All authors have read and agreed to the published version of the manuscript.

Funding: Brazilian government research agencies National Council for Scientific and Technological Development (CNPq), Coordination for the Improvement of Higher Education Personnel (CAPES), and Santa Catarina Research Foundation (FAPESC) are acknowledged for providing the financial support for this research. This research received no external funding.

Institutional Review Board Statement: Not applicable.

Informed Consent Statement: Not applicable.

Data Availability Statement: Not applicable.

Acknowledgments: LCP (UFSC) and LINDEN (UFSC) are acknowledged for TGA and DLS analysis, respectively.

Conflicts of Interest: The authors declare no conflict of interest.

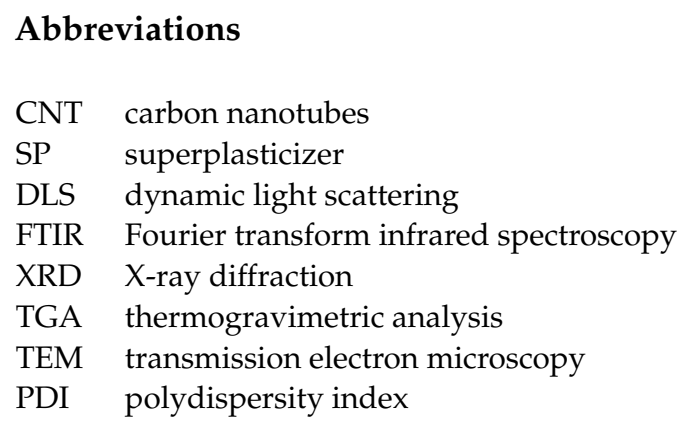




\section{References}

1. Kamedulski, P.; Lukaszewicz, J.P.; Witczak, L.; Szroeder, P.; Ziolkowski, P. The importance of structural factors for the electrochemical performance of graphene/carbon nanotube/melamine powders towards the catalytic activity of oxygen reduction reaction. Materials 2021, 14, 2448. [CrossRef] [PubMed]

2. Ma, P.C.; Siddiqui, N.A.; Marom, G.; Kim, J.K. Dispersion and functionalization of carbon nanotubes for polymer-based nanocomposites: A review. Compos. A Appl. Sci. Manuf. 2010, 41, 1345-1367. [CrossRef]

3. Mohsen, M.O.; Al-Nuaimi, N.; Abu Al-Rub, R.K.; Senouci, A.; Bani-Hani, K.A. Effect of mixing duration on flexural strength of multi walled carbon nanotubes cementitious composites. Constr. Build. Mater. 2016, 126, 586-598. [CrossRef]

4. Konsta-Gdoutos, M.S.; Batis, G.; Danoglidis, P.A.; Zacharopoulou, A.K.; Zacharopoulou, E.K.; Falara, M.G.; Shah, S.P. Effect of $\mathrm{CNT}$ and CNF loading and count on the corrosion resistance, conductivity and mechanical properties of nanomodified OPC mortars. Constr. Build. Mater. 2017, 147, 48-57. [CrossRef]

5. Liew, K.M.; Kai, M.F.; Zhang, L.W. Carbon nanotube reinforced cementitious composites: An overview. Compos. A Appl. Sci. Manuf. 2016, 91, 301-323. [CrossRef]

6. Silvestro, L.; Gleize, P.J.P. Effect of carbon nanotubes on compressive, flexural and tensile strengths of Portland cement-based materials: A systematic literature review. Constr. Build. Mater. 2020, 264, 120237. [CrossRef]

7. Banerjee, S.; Hemraj-Benny, T.; Wong, S.S. Covalent surface chemistry of single-walled carbon nanotubes. Adv. Mater. 2005, 17, 17-29. [CrossRef]

8. Jarolim, T.; Labaj, M.; Hela, R.; Michnova, K. Carbon Nanotubes in Cementitious Composites: Dispersion, Implementation, and Influence on Mechanical Characteristics. Adv. Mater. Sci. Eng. 2016, 2016, 1-6. [CrossRef]

9. Mendoza, O.; Sierra, G.; Tobón, J.I. Influence of super plasticizer and $\mathrm{Ca}(\mathrm{OH}) 2$ on the stability of functionalized multi-walled carbon nanotubes dispersions for cement composites applications. Constr. Build. Mater. 2013, 47, 771-778. [CrossRef]

10. Zou, B.; Chen, S.J.; Korayem, A.H.; Collins, F.; Wang, C.; Duan, W.H. Effect of ultrasonication energy on engineering properties of carbon nanotube reinforced cement pastes. Carbon 2015, 85, 212-220. [CrossRef]

11. Isfahani, F.T.; Li, W.; Redaelli, E. Dispersion of multi-walled carbon nanotubes and its effects on the properties of cement composites. Cem. Concr. Compos. 2016, 74, 154-163. [CrossRef]

12. De Siqueira, J.E.L.; Gleize, P.J.P. Effect of carbon nanotubes sonication on mechanical properties of cement pastes. Rev. IBRACON Estruturas Mater. 2020, 13, 455-463. [CrossRef]

13. Alrekabi, S.; Cundy, A.; Lampropoulos, A.; Savina, I. Experimental Investigation on the Effect of Ultrasonication on Dispersion and Mechanical Performance of Multi-Wall Carbon Nanotube-Cement Mortar Composites. Int. J. Civil Environ. Struct. Constr. Archit. Eng. 2016, 10, 11.

14. Assi, L.N.; Al-hamadani, Y.A.J.; Eddie, E.; Soltangharaei, V.; Ziehl, P. Effect of Sonicated Deionized Water on The Early Age Behavior of Portland Cement-Based Concrete and Paste. Constr. Build. Mater. 2020, 247, 118571. [CrossRef]

15. MacLeod, A.J.N.; Gates, W.P.; Collins, F. Durability characterisation of portland cement-carbon nanotube nanocomposites. Materials 2020, 13, 4097. [CrossRef] [PubMed]

16. del Carmne Camacho, M.; Galao, O.; Baeza, F.J.; Zornoza, E.; Garcés, P. Mechanical properties and durability of CNT cement composites. Materials 2014, 7, 1640-1651. [CrossRef]

17. Cui, H.; Jin, Z.; Zheng, D.; Tang, W.; Li, Y.; Yun, Y.; Lo, T.Y.; Xing, F. Effect of carbon fibers grafted with carbon nanotubes on mechanical properties of cement-based composites. Constr. Build. Mater. 2018, 181, 713-720. [CrossRef]

18. Batiston, E.; de Matos, P.R.; Gleize, P.J.P.; Fediuk, R.; Klyuev, S.; Vatin, N.; Karelina, M. Combined functionalization of carbon nanotubes (CNT) fibers with $\mathrm{H}_{2} \mathrm{SO}_{4} / \mathrm{HNO}_{3}$ and $\mathrm{Ca}(\mathrm{OH})_{2}$ for addition in cementitious matrix. Fibers 2021, 9, 14. [CrossRef]

19. Bogas, J.A.; Hawreen, A.; Olhero, S.; Ferro, A.C.; Guedes, M. Selection of dispersants for stabilization of unfunctionalized carbon nanotubes in high pH aqueous suspensions: Application to cementitious matrices. Appl. Surf. Sci. 2019, 463, 169-181. [CrossRef]

20. Jorio, A.; Saito, R. Raman spectroscopy for carbon nanotube applications. J. Appl. Phys. 2021, 129, 021102. [CrossRef]

21. Janowska-Renkas, E. The influence of the chemical structure of polycarboxylic superplasticizers on their effectiveness in cement pastes. Procedia Eng. 2015, 108, 575-583. [CrossRef]

22. Choi, H.; Kang, D.; Seo, G.S.; Chung, W. Effect of Some Parameters on the Compressive Strength of MWCNT-Cement Composites. Adv. Mater. Sci. Eng. 2015, 2015, 1-8. [CrossRef]

23. Cui, H.; Yan, X.; Monasterio, M.; Xing, F. Effects of various surfactants on the dispersion of MWCNTs-OH in aqueous solution. Nanomaterials 2017, 7, 262. [CrossRef]

24. Li, Z.; Corr, D.J.; Han, B.; Shah, S.P. Investigating the effect of carbon nanotube on early age hydration of cementitious composites with isothermal calorimetry and Fourier transform infrared spectroscopy. Cem. Concr. Compos. 2020, 107, 103513. [CrossRef]

25. Khitab, A.; Ahmad, S.; Khushnood, R.A.; Rizwan, S.A.; Ferro, G.A.; Restuccia, L.; Ali, M.; Mehmood, I. Fracture toughness and failure mechanism of high performance concrete incorporating carbon nanotubes. Frat. Integrita Strutt. 2017, 11, 238-248. [CrossRef]

26. Elkashef, M.; Wang, K.; Abou-Zeid, M.N. Acid-treated carbon nanotubes and their effects on mortar strength. Front. Struct. Civ. Eng. 2016, 10, 180-188. [CrossRef]

27. Attal, S.; Thiruvengadathan, R.; Regev, O. Determination of the concentration of single-walled carbon nanotubes in aqueous dispersions using UV-visible absorption spectroscopy. Anal. Chem. 2006, 78, 8098-8104. [CrossRef] [PubMed] 
28. Jiang, L.; Gao, L.; Sun, J. Production of aqueous colloidal dispersions of carbon nanotubes. J. Colloid Interface Sci. 2003, 260, 89-94. [CrossRef]

29. de Matos, P.R.; Sakata, R.D.; Onghero, L.; Uliano, V.G.; de Brito, J.; Campos, C.E.M.; Gleize, P.J.P. Utilization of ceramic tile demolition waste as supplementary cementitious material: An early-age investigation. J. Build. Eng. 2021, 38, 102187. [CrossRef]

30. De Larrard, F.; Ferraris, C.F.; Sedran, T. Fresh concrete: A Herschel-Bulkley material. Mater. Struct. Constr. 1996, 31, 494-498. [CrossRef]

31. Kantro, D. Influence of Water-Reducing Admixtures on Properties of Cement Paste-A Miniature Slump Test. Cem. Concr. Aggreg. 1980, 2, 95. [CrossRef]

32. American Society for Testing and Materials. Standard Practice for Use of Unbonded Caps in Determination of Compressive Strength of Hardened Concrete Cylinders; ASTM C1231/C1231M-15; American Society for Testing and Materials: West Conshohocken, PA, USA, 2012.

33. Snellings, R.; Chwast, J.; Cizer, Ö.; De Belie, N.; Dhandapani, Y.; Durdzinski, P.; Elsen, J.; Haufe, J.; Hooton, D.; Patapy, C.; et al. Report of TC 238-SCM: Hydration stoppage methods for phase assemblage studies of blended cements-Results of a round robin test. Mater. Struct. Constr. 2018, 51, 111. [CrossRef]

34. Zhang, L.W.; Kai, M.F.; Liew, K.M. Evaluation of microstructure and mechanical performance of CNT-reinforced cementitious composites at elevated temperatures. Compos. A Appl. Sci. Manuf. 2017, 95, 286-293. [CrossRef]

35. Dai, W.; Wang, J.; Gan, X.; Wang, H.; Su, X.; Xi, C. A systematic investigation of dispersion concentration and particle size distribution of multi-wall carbon nanotubes in aqueous solutions of various dispersants. Colloids Surf. A Physicochem. Eng. Asp. 2020, 589. [CrossRef]

36. Ding, L.; Jia, Z.; Sun, H.; Pan, Y.; Zhao, J. Estimation of mechanical performance, thermal stability and flame retardancy of high-impact polystyrene/surface-modified APP/carboxylic-functionalized MWCNTs nanocomposites. Polymers 2019, 11, 615. [CrossRef] [PubMed]

37. Alafogianni, P.; Dassios, K.; Farmaki, S.; Antiohos, S.K.; Matikas, T.E.; Barkoula, N.M. On the efficiency of UV-vis spectroscopy in assessing the dispersion quality in sonicated aqueous suspensions of carbon nanotubes. Colloids Surf. A Physicochem. Eng. Asp. 2016, 495, 118-124. [CrossRef]

38. Parveen, S.; Rana, S.; Fangueiro, R.; Paiva, M.C. Characterizing dispersion and long term stability of concentrated carbon nanotube aqueous suspensions for fabricating ductile cementitious composites. Powder Technol. 2017, 307, 1-9. [CrossRef]

39. Reales, O.A.M.; Toledo Filho, R.D. A review on the chemical, mechanical and microstructural characterization of carbon nanotubes-cement based composites. Constr. Build. Mater. 2017, 154, 697-710. [CrossRef]

40. Chowdhury, D.F.; Cui, Z.F. Carbon nanotube length reduction techniques, and characterisation of oxidation state using quasielastic light scattering. Carbon 2011, 49, 862-868. [CrossRef]

41. Hou, P.; Shi, J.; Prabakar, S.; Cheng, X.; Wang, K.; Zhou, X.; Shah, S.P. Effects of mixing sequences of nanosilica on the hydration and hardening properties of cement-based materials. Constr. Build. Mater. 2020, 263, 120226. [CrossRef]

42. Dehghani, M.H.; Zarei, A.; Yousefi, M. Efficiency of ultrasound for degradation of an anionic surfactant from water: Surfactant determination using methylene blue active substances method. MethodsX 2019, 6, 805-814. [CrossRef] [PubMed]

43. Wang, Y.; Mei, Y.; Wang, Q.; Wei, W.; Huang, F.; Li, Y.; Li, J.; Zhou, Z. Improved fracture toughness and ductility of PLA composites by incorporating a small amount of surface-modified helical carbon nanotubes. Compos. B Eng. 2019, 162, 54-61. [CrossRef]

44. Lavorgna, M.; Romeo, V.; Martone, A.; Zarrelli, M.; Giordano, M.; Buonocore, G.G.; Qu, M.Z.; Fei, G.X.; Xia, H.S. Silanization and silica enrichment of multiwalled carbon nanotubes: Synergistic effects on the thermal-mechanical properties of epoxy nanocomposites. Eur. Polym. J. 2013, 49, 428-438. [CrossRef]

45. Lee, J.H.; Rhee, K.Y.; Park, S.J. Silane modification of carbon nanotubes and its effects on the material properties of carbon/CNT/epoxy three-phase composites. Compos. A Appl. Sci. Manuf. 2011, 42, 478-483. [CrossRef]

46. Hamed Mashhadzadeh, A.; Fereidoon, A.; Ghorbanzadeh Ahangari, M. Surface modification of carbon nanotubes using 3aminopropyltriethoxysilane to improve mechanical properties of nanocomposite based polymer matrix: Experimental and Density functional theory study. Appl. Surf. Sci. 2017, 420, 167-179. [CrossRef]

47. Avilés, F.; Sierra-Chi, C.A.; Nistal, A.; May-Pat, A.; Rubio, F.; Rubio, J. Influence of silane concentration on the silanization of multiwall carbon nanotubes. Carbon 2013, 57, 520-529. [CrossRef]

48. Li, S.; Wang, Z.; Jia, J.; Hou, C.; Hao, X.; Zhang, H. Preparation of hydroxyl and (3-aminopropyl)triethoxysilane functionalized multiwall carbon nanotubes for use as conductive fillers in the polyurethane composite. Polym. Compos. 2018, 39, 1212-1222. [CrossRef]

49. Shanmugharaj, A.M.; Bae, J.H.; Lee, K.Y.; Noh, W.H.; Lee, S.H.; Ryu, S.H. Physical and chemical characteristics of multiwalled carbon nanotubes functionalized with aminosilane and its influence on the properties of natural rubber composites. Compos. Sci. Technol. 2007, 67, 1813-1822. [CrossRef]

50. Velasco-Santos, C.; Martinez-Hernandez, A.L.; Brostow, W.; Castaño, V.M. Influence of silanization treatment on thermomechanical properties of multiwalled carbon nanotubes: Poly(methylmethacrylate) nanocomposites. J. Nanomater. 2011, 2011, 1-9. [CrossRef]

51. Jiang, S.; Shan, B.; Ouyang, J.; Zhang, W.; Yu, X.; Li, P.; Han, B. Rheological properties of cementitious composites with nano/fiber fillers. Constr. Build. Mater. 2018, 158, 786-800. [CrossRef] 
52. Chuah, S.; Pan, Z.; Sanjayan, J.G.; Wang, C.M.; Duan, W.H. Nano reinforced cement and concrete composites and new perspective from graphene oxide. Constr. Build. Mater. 2014, 73, 113-124. [CrossRef]

53. da Silva Andrade Neto, J.; Santos, T.A.; de Andrade Pinto, S.; Dias, C.M.R.; Ribeiro, D.V. Effect of the combined use of carbon nanotubes (CNT) and metakaolin on the properties of cementitious matrices. Constr. Build. Mater. 2021, 271, 121903. [CrossRef]

54. Reales, O.A.M.; Arias Jaramillo, Y.P.; Ochoa Botero, J.C.; Delgado, C.A.; Quintero, J.H.; Toledo Filho, R.D. Influence of MWCNT/surfactant dispersions on the rheology of Portland cement pastes. Cem. Concr. Res. 2018, 107, 101-109. [CrossRef]

55. Azevedo, N.H.; de Matos, P.R.; Gleize, P.J.P.; Betioli, A.M. Effect of thermal treatment of SiC nanowhiskers on rheological, hydration, mechanical and microstructure properties of Portland cement pastes. Cem. Concr. Compos. 2021, 117, 103903. [CrossRef]

56. Mendoza Reales, O.A.; Duda, P.; Silva, E.C.C.M.; Paiva, M.D.M.; Filho, R.D.T. Nanosilica particles as structural buildup agents for 3D printing with Portland cement pastes. Constr. Build. Mater. 2019, 219, 91-100. [CrossRef]

57. Hou, P.K.; Kawashima, S.; Wang, K.J.; Corr, D.J.; Qian, J.S.; Shah, S.P. Effects of colloidal nanosilica on rheological and mechanical properties of fly ash-cement mortar. Cem. Concr. Compos. 2013, 35, 12-22. [CrossRef]

58. da Silva Andrade, D.; da Silva Rêgo, J.H.; Cesar Morais, P.; Frías Rojas, M. Chemical and mechanical characterization of ternary cement pastes containing metakaolin and nanosilica. Constr. Build. Mater. 2018, 159, 18-26. [CrossRef]

59. Scrivener, K.L.; Juilland, P.; Monteiro, P.J.M. Advances in understanding hydration of Portland cement. Cem. Concr. Res. 2015, 78, 38-56. [CrossRef]

60. Bullard, J.W.; Jennings, H.M.; Livingston, R.A.; Nonat, A.; Scherer, G.W.; Schweitzer, J.S.; Scrivener, K.L.; Thomas, J.J. Mechanisms of cement hydration. Cem. Concr. Res. 2011, 41, 1208-1223. [CrossRef]

61. Macleod, A.J.N.; Collins, F.G.; Duan, W. Effects of carbon nanotubes on the early-age hydration kinetics of Portland cement using isothermal calorimetry. Cem. Concr. Compos. 2021, 119, 103994. [CrossRef]

62. Nadiv, R.; Shtein, M.; Refaeli, M.; Peled, A.; Regev, O. The critical role of nanotube shape in cement composites. Cem. Concr. Compos. 2016, 71, 166-174. [CrossRef]

63. Wang, B.; Pang, B. Properties improvement of multiwall carbon nanotubes-reinforced cement-based composites. J. Compos. Mater. 2020, 54, 2379-2387. [CrossRef]

64. Sikora, P.; Abd Elrahman, M.; Chung, S.Y.; Cendrowski, K.; Mijowska, E.; Stephan, D. Mechanical and microstructural properties of cement pastes containing carbon nanotubes and carbon nanotube-silica core-shell structures, exposed to elevated temperature. Cem. Concr. Compos. 2019, 95, 193-204. [CrossRef]

65. Mendoza Reales, O.A.; Pearl, W.C.; Paiva, M.D.M.; Miranda, C.R.; Toledo Filho, R.D. Effect of a commercial dispersion of multi walled carbon nanotubes on the hydration of an oil well cementing paste. Front. Struct. Civ. Eng. 2016, 10, 174-179. [CrossRef]

66. Azevedo, A.R.G.; Cecchin, D.; Carmo, D.F.; Silva, F.C.; Campos, C.M.O.; Shtrucka, T.G.; Monteiro, S.N. Analysis of the compactness and properties of the hardened state of mortars with recycling of construction and demolition waste (CDW). J. Mater. Res. Technol. 2020, 9, 5942-5952. [CrossRef]

67. Ahmed, H.; Bogas, J.A.; Guedes, M.; Pereira, M.F.C. Dispersion and reinforcement efficiency of carbon nanotubes in cementitious composites. Mag. Concr. Res. 2019, 71, 408-423. [CrossRef]

68. Scrivener, K.; Snellings, R.; Lothenbach, B. A Practical Guide to Microstructural Analysis of Cementitious Materials; CRC Press: Boca Raton, FL, USA, 2018; ISBN 9781498738675.

69. Lee, S.; Lee, D.K. What is the proper way to apply the multiple comparison test? Korean J. Anesthesiol. 2018, 71, 353-360. [CrossRef]

70. Azevedo, A.; De Matos, P.; Marvila, M.; Sakata, R.; Silvestro, L.; Gleize, P.; De Brito, J. Rheology, hydration, and microstructure of portland cement pastes produced with ground açaí fibers. Appl. Sci. 2021, 11, 3036. [CrossRef]

71. Naqi, A.; Abbas, N.; Zahra, N.; Hussain, A.; Shabbir, S.Q. Effect of multi-walled carbon nanotubes (MWCNTs) on the strength development of cementitious materials. J. Mater. Res. Technol. 2019, 8, 1203-1211. [CrossRef]

72. Chen, J.; Akono, A.T. Influence of multi-walled carbon nanotubes on the hydration products of ordinary Portland cement paste. Cem. Concr. Res. 2020, 137, 106197. [CrossRef]

73. Alatawna, A.; Birenboim, M.; Nadiv, R.; Buzaglo, M.; Peretz-Damari, S.; Peled, A.; Regev, O.; Sripada, R. The effect of compatibility and dimensionality of carbon nanofillers on cement composites. Constr. Build. Mater. 2020, 232, 117141. [CrossRef]

74. Lothenbach, B.; Le Saout, G.; Gallucci, E.; Scrivener, K. Influence of limestone on the hydration of Portland cements. Cem. Concr. Res. 2008, 38, 848-860. [CrossRef]

75. Berodier, E.; Scrivener, K. Understanding the filler effect on the nucleation and growth of C-S-H. J. Am. Ceram. Soc. 2014, 97, 3764-3773. [CrossRef]

76. De Matos, P.R.; Andrade Neto, J.S.; Campos, C.E.M. Is the R index accurate to assess the preferred orientation of portlandite in cement pastes? Constr. Build. Mater. 2021, 292, 123471. [CrossRef] 